\title{
Propuesta de un indicador de bienestar multidimensional de uso del tiempo y condiciones de vida aplicado a Colombia, el Ecuador, México y el Uruguay
}

\author{
Evelyn Benvin, Elizabeth Rivera y Varinia Tromben
}

En el presente artículo se invita a discutir el marco conceptual y metodológico de un indicador de bienestar multidimensional, que incluye una dimensión de uso del tiempo junto con dimensiones de condiciones de vida usualmente incorporadas en este tipo de análisis. Las carencias identificadas mediante los componentes de este indicador se entienden como un obstáculo para el desarrollo de las capacidades humanas. El objetivo último es mirar más allá de las métricas monetarias e identificar los indicadores que mejor explican cómo la población, en lugar de las economías, se está desarrollando. En este análisis se emplea la metodología de identificación y agregación de Alkire y Foster (2007 y 2013) y se muestran los resultados para cuatro países de la región (Colombia, Ecuador, México y Uruguay) utilizando encuestas sobre el uso del tiempo y distinguiendo, además, por tipo de hogar.

PALABRAS CLAVE

CLASIFICACIÓN JEL

AUTORES
Bienestar social, empleo de la mujer, igualdad de remuneración, indicadores sociales, estadísticas del uso del tiempo, Colombia, Ecuador, México, Uruguay

$\mathrm{I} 32, \mathrm{~J} 16, \mathrm{~J} 22, \mathrm{O} 54$

Evelyn Benvin es Asesora del Consejo Nacional de la Infancia, Ministerio Secretaría General de la Presidencia. ebenvin@consejoinfancia.gob.cl

Elizabeth Rivera es Asesora del Consejo Nacional de la Infancia, Ministerio Secretaría General de la Presidencia.erivera@consejoinfancia.gob.cl

Varinia Tromben es Oficial Asociado de Asuntos Económicos de la División de Desarrollo Social de la Comisión Económica para América Latina y el Caribe (CEPAL). varinia.tromben@cepal.org 


\section{I}

\section{Introducción}

En el indicador propuesto se integran componentes normativos y políticos respecto de la división sexual del trabajo, entendida esta como la desigual distribución de las actividades relacionadas con el trabajo no remunerado (TNR) — que incluye el trabajo doméstico y de cuidado y el trabajo remunerado (TR) entre hombres y mujeres-. Se hace necesario entonces conceptualizar, establecer y medir aproximaciones a la "pobreza de tiempo" y condiciones de vida desde una perspectiva de género y capacidades. Con ese fin, primero se visualizan las actividades cotidianas de un individuo (comenzando por la agrupación de aquellas tales como TNR y TR), para luego identificar y definir los umbrales mínimos o máximos que un individuo necesita alcanzar para no ser clasificado como pobre en la distribución real de su tiempo. Asimismo, también se establecen los umbrales con que se identifica a la población con carencias en las demás dimensiones de este indicador.

En lo conceptual, uno de los desafíos de este artículo es explicar las implicaciones que significa considerar el tiempo como un activo y desde el enfoque de capacidades articular sus consecuencias teóricas en

$\square$ Este artículo corresponde a una versión breve del trabajo realizado durante el año 2014 en la División de Asuntos de Género de la Comisión Económica para América Latina y el Caribe (CEPAL), en el marco del proyecto "Promoción de la igualdad en América Latina y el Caribe" financiado por el Ministerio de Relaciones Exteriores de Noruega. un indicador mutidimensional, que incluye a la vez el tiempo y las condiciones de vida. Otro desafío central es generar argumentos que promuevan el desarrollo de indicadores de uso de tiempo y condiciones de vida desde una perspectiva de múltiples dimensiones, así como complementar los indicadores de pobreza de ingresos con el propósito de diseñar y monitorear estrategias y programas orientados a la superación de la pobreza. Dicho indicador contribuye a las políticas públicas pudiendo ser utilizado para monitorear políticas relacionadas con el cuidado, la familia (asignaciones familiares), el empleo, el transporte, la política fiscal y otros. También permitiría evidenciar parte de las barreras aún existentes para la plena incorporación de las mujeres al mercado laboral, como asimismo la carencia de justicia distributiva en el interior del hogar.

El presente trabajo se divide en cuatro partes. Luego de esta Introducción en que se da cuenta de la motivación, la relevancia y los objetivos del indicador de bienestar multidimensional de tiempo y condiciones de vida propuesto, en la sección II se desarrollan los aspectos conceptuales inherentes al tiempo; a su vez, la sección III se centra en la metodología utilizada para el desarrollo del indicador: unidad de análisis, y dimensiones y nociones introductorias respecto de la definición de umbrales; luego en la sección IV se presentan los resultados del indicador utilizando las encuestas de uso del tiempo de Colombia, el Ecuador, México y el Uruguay. Por último, en la sección $\mathrm{V}$ se realizan algunas reflexiones finales sobre las potencialidades y limitaciones de este indicador.

\section{II \\ ¿Por qué el tiempo importa para el bienestar y el desarrollo de capacidades?}

\section{El tiempo como un aspecto central para el bienestar}

El bienestar es un concepto multidimensional en que se consideran tanto factores tangibles como intangibles. El tiempo es uno de los factores intangibles, ya que la libertad y las oportunidades de un individuo para asignar su tiempo a las actividades que él o ella valora son esenciales para su bienestar y el desarrollo de sus capacidades (Robeyns, 2003). En este sentido, el tiempo es un recurso con 
alto impacto en la creación y acumulación de activos y otros recursos, y sus restricciones ${ }^{1}$ se constituyen como barreras a los procesos de conversión de capacidades ${ }^{2}$ en funcionamientos efectivos. Estas restricciones provienen de constructos sociales, culturales e históricos que tienen efectos tanto a nivel personal, del hogar y social ${ }^{3}$ (Carrasco, Borderías y Torns, 2011). De esta forma, la "pobreza de tiempo" se entendería como una restricción a la libertad y a las oportunidades de definir el tiempo que un individuo dedica a las actividades que valora, lo que tiene efectos negativos en el bienestar presente $\mathrm{y}$ futuro de las personas.

La pobreza de tiempo, derivada de la carga excesiva que exige el trabajo remunerado, puede llegar a repercutir negativamente en el bienestar de un hogar, dado que restringe el tiempo que se puede dedicar al trabajo doméstico y cuidado de los miembros dependientes del hogar (Robeyns, 2003). Pero también se puede plantear lo contrario: lo que genera la "pobreza de tiempo" es el exceso de trabajo no remunerado, sobre todo por su desigual distribución entre hombres y mujeres. Esta situación afecta mayormente a quienes suelen llevar a cabo la mayor parte del trabajo doméstico: las mujeres.

La vulnerabilidad que implica la pobreza de tiempo tiene efectos diferenciados originados por las restricciones temporales de las personas, quienes dependerían de sus propias características y capacidades para sobrellevar las limitaciones resultantes de la carencia de tiempo (Ballet y otros, 2014). Es decir, los niveles de vulnerabilidad que afectan a los individuos son parte de sus respuestas heterogéneas a la pobreza de tiempo y de sus expresiones mediante restricciones al bienestar individual y familiar. Bittman y otros (2005) hacen hincapié en la relación entre la pobreza de tiempo y la exclusión social, la que sería una relación inversa dado que a una menor asignación de tiempo libre podría aumentar la exclusión social de la población.

Una corriente de pensamiento distinta podría argumentar que no es claro el impacto en el bienestar de las desigualdades de género producidas por la división sexual del trabajo, dado que la sobrecarga de las mujeres en el trabajo doméstico de los hogares puede basarse en una decisión libre, informada y consensuada entre los

\footnotetext{
${ }^{1}$ Restricciones tales como la división sexual del trabajo y el monopolio del poder en la toma de decisiones de un hogar.

2 Más adelante se definen los conceptos de capacidades y funcionamientos.

${ }^{3}$ Específicamente, durante la asignación de su tiempo un individuo interactúa con los factores que intervienen en el proceso de transformación de los funcionamientos individuales en capacidades.
}

miembros de un hogar. Y esta sobrecarga de trabajo puede representar la más alta valorización entre las actividades que un individuo tiene oportunidad y libertad de elegir. En este caso, la sobrecarga de trabajo remunerado puede no implicar una restricción de los factores de transformación de las capacidades en funcionamientos efectivos y, por tanto, no impactar de manera negativa en el bienestar de los individuos ${ }^{4}$. No obstante, según las autoras del presente estudio, esta en una interpretación conservadora del enfoque de capacidades, porque asume que los individuos al tomar decisiones informadas, basadas en sus preferencias individuales y con libertad, no verán afectado su bienestar. Y aun cuando las decisiones sean informadas y con libertad, es posible que en una sociedad las decisiones de los individuos estén altamente influenciadas por las normas culturales y las expectativas sociales relativas a los roles de géneros tradicionales y la división sexual del trabajo, las que supeditan a las mujeres al mundo privado y las excluyen o desincentivan de participar en el mundo público.

\section{El tiempo como recurso}

Durante la década de 1970, en la mayor parte de la conceptualización sobre pobreza de tiempo este se definió como un "recurso". Vickery (1977) y Gronau (1977) lo definieron en sus modelos como un recurso que puede ser utilizado en actividades productivas en el mercado, como TNR destinado al cuidado en el interior de los hogares, o invertido en actividades personales y descanso. Si el tiempo es considerado un activo, este correspondería a un tipo especial porque se trata de un recurso fijo e igualitario para toda la población (Goodin y otros, 2008). Aunque estas características diferenciarían al tiempo y los ingresos, Johnstone (1960) argumenta que estos tienen un problema en común: cómo asignarlos diariamente de manera eficiente y exitosa de acuerdo con las preferencias de cada persona u hogar. Esta pregunta se comprende en un contexto donde gran parte de la población dispone de ingresos y tiempo limitados que deben ser distribuidos entre una variedad de necesidades y alternativas de gasto e inversión.

Bardasi y Wodon (2009) plantean que, a diferencia de los ingresos, asignar más tiempo a una actividad no siempre es mejor. Debido a que el tiempo es un recurso limitado y que, por tanto, asignar más de este al trabajo remunerado o no remunerado necesariamente implica

\footnotetext{
${ }^{4}$ Existe una amplia literatura sobre las críticas de la economía feminista a los enunciados de la "nueva economía de la familia" que se puede consultar en Carrasco (1991).
} 
menos tiempo para el descanso y entretención, lo que podría redundar en un mayor nivel de "pobreza de tiempo". Sin embargo, si un individuo sacrifica consumo entre ciertos bienes básicos con el objeto de acceder a otros bienes básicos, su función de utilidad podría mantenerse igual y, por lo tanto, no considerar este cambio como un factor que repercute negativamente en el bienestar de los individuos.

En la teoría de la conservación de los recursos, estos se definen como "características personales, condiciones o energías que son valoradas por el individuo o que sirven como un medio para la consecución de otros recursos" (Hobfoll, 1989, citado en Adkins y Premeaux, 2012). Esta definición permite considerar el tiempo como un recurso relevante para los individuos que lo valoran. Este punto podría generar una distancia analítica entre el tiempo y los ingresos porque, en general, se asume que los ingresos siempre son muy valorizados por los individuos y el tiempo no necesariamente lo es. Por consiguiente, es relevante destacar que no todos los recursos tienen la misma valorización por parte de los individuos, y que las preferencias individuales y los factores socioculturales cumplen un papel en esta valorización.

La implicancia de la teoría de la conservación de los recursos y su relación con la carencia del uso del tiempo radican en que, al igual que el ingreso, el beneficio marginal de cada minuto u hora depende del nivel de uso del recurso tiempo (o intensidad en el uso). En otras palabras, el tiempo por sí mismo puede representar una carencia, pero la calidad del tiempo remanente o sin uso por individuo, y que potencialmente puede ser redistribuido en diferentes actividades, es un componente que debe ser tomado en consideración por un indicador de pobreza del tiempo. Burchardt (2010) destaca que el rendimiento del uso del tiempo varía entre la población como resultado de las diferencias de ingresos en esta. Así, por ejemplo, una hora de un trabajador de los deciles de mayores ingresos puede ser transformada en una de muchas actividades. Sin embargo, las opciones son más restringidas para aquellos trabajadores de los deciles de menores ingresos, dado que este grupo de la población tiene menos posibilidades de comprar en el mercado servicios que amplíen sus oportunidades a actividades distintas del trabajo doméstico.

Sin embargo, si el tiempo es considerado o no un recurso no es una limitante para su conceptualización como un facilitador u obstaculizador de "capacidades" $\mathrm{y}$ sus potenciales repercusiones en el bienestar.

\section{El tiempo como un facilitador $\mathrm{u}$ obstaculizador de capacidades}

Con el concepto de capacidades ${ }^{5}$ se hace referencia al conjunto de vectores de funcionamientos o de "doing/ hacer" y "being/ser", los que indican la capacidad que tiene un individuo para ser libre en cuanto a llevar el tipo de vida que él o ella valore (Sen, 2000). Considerar al tiempo como un factor que en presencia de libertad y oportunidades ${ }^{6}$ es facilitador de la transformación de capacidades en funcionamientos efectivos ${ }^{7}$ para el trabajo remunerado y no remunerado, implica que las capacidades de los individuos no deben ser evaluadas en virtud de los recursos y activos que poseen, sino por el ejercicio efectivo de su libertad y oportunidades de asignar su tiempo entre las actividades que estos valoran. La relevancia de la asignación del tiempo entre las actividades que un individuo valora radica, por una parte, en su estrecha vinculación con el bienestar (Stiglitz, Sen y Fitoussi, 2009) y, por otra, en la presencia de justicia distributiva.

El enfoque de capacidades permite una más amplia comprensión de la desigualdad entre los sexos que aquella focalizada en la comparación de los bienes primarios o recursos (Sen, 2000). La distribución y asignación del tiempo pueden ser consideradas el resultado de la interrelación de las desigualdades a nivel micro, es decir, en el contexto de la distribución de los recursos y el uso del poder en una unidad familiar. Es así que, Brighouse y Robeyns (2010, pág. 215) argumentan que las inequidades de género impactan en el acceso a oportunidades para combatir las inequidades entre los

\footnotetext{
5 Sen (1992 y 2000) y Nussbaum (2011) introducen el concepto de "capacidades" en el estudio de la justicia social y las libertades, respectivamente. El enfoque de las capacidades de Sen (1992 y 2000) es un "marco teórico moral" que propone que las estructuras sociales deben ser evaluadas según el alcance de las libertades de las personas para promover o alcanzar los funcionamientos que valoran. Otra característica del enfoque de las capacidades es el papel de las consideraciones morales y los principios éticos, y su preocupación por la justicia, de manera que cada persona alcance el desarrollo de las capacidades que valora asegurando la igualdad de oportunidades para todos dentro del "universo de capacidades" (Alkire, 2002).

${ }^{6}$ Las oportunidades para el enfoque de capacidades se refieren a los funcionamientos, y estos son definidos como lo que un individuo es capaz de hacer o ser.

${ }^{7}$ Robeyns (2003) establece que la diferencia entre funcionamiento y capacidades es similar a la diferencia entre los logros y la libertad de alcanzarlos o la diferencia entre los resultados y las oportunidades. Las capacidades en su conjunto corresponden a la libertad que un individuo tiene para alcanzar lo que ella o él valoran (pág. 63).
} 
cuidadores y los no cuidadores y la división de género dentro de los hogares. Este argumento agrega algunas complejidades adicionales a la pregunta acerca de las medidas o indicadores de pobreza del tiempo que podrían incluir el concepto de justicia socioeconómica, libertad y el ejercicio individual de la agencia.

Según Fraser y Honneth (2006) y Fraser (2009), existen dos tipos de reivindicaciones de justicia social: las reivindicaciones distributivas más justas de recursos y las reivindicaciones de reconocimiento. Fraser (2009) integra ambas formas de reivindicaciones en un enfoque que permite, desde una perspectiva normativa y metodológica, diseñar un indicador que contribuya al monitoreo de las políticas públicas ${ }^{8}$. Para los efectos de esta investigación, es importante reflexionar sobre los diferentes enfoques teóricos que abordan la justicia socioeconómica desde el reconocimiento. Dicha reflexión contribuye a responder las siguientes preguntas: ¿cómo resolver la demanda de justicia socioeconómica en la (re)distribución del tiempo entre el TR y el TNR?, ¿bajo qué contextos o a qué nivel —individual o colectivo- interactúan ambas aproximaciones a la justicia socioeconómica (reconocimiento y distribución de recursos)?, ¿cómo se hace justicia a través del reconocimiento y cómo se complementa con la distribución de recursos?

Uno de los objetivos de analizar el tiempo como facilitador u obstaculizador de capacidades a nivel individual y en el interior del hogar es contribuir a cambiar los patrones de distribución de tiempo basados en la desigualdad y la ausencia de libertad y justicia distributiva.

De acuerdo con esta idea, la pobreza de tiempo representa una restricción al ejercicio de los "doing/ hacer" y "being/ser" y es el resultado de las carencias en el acceso a los espacios de las capacidades. Sen (1992 y 2000) pone énfasis en las complementariedades entre las diferentes capacidades de una persona y su dependencia de las características de los otros y del entorno en que las personas viven, incluida la justicia. Aunque tienen valor intrínseco, muchas de estas capacidades son también un medio para expandir otras capacidades que permiten incrementar el bienestar de los individuos.

Los factores de conversión o transformación son también sociales y, como argumentan Brighouse y Robeyns

\footnotetext{
8 Políticas públicas que tienen por objetivo la redistribución de los recursos y el reconocimiento en pos de mayor justicia social.
}

(2010), es este aspecto del enfoque de capacidades el que permite un argumento en favor de la eliminación de las desigualdades estructurales entre hombres y mujeres, que afectan la capacidad de estas para transformar medios o recursos en funcionamientos.

Desde el enfoque de capacidades y género, la pobreza de tiempo requiere una conceptualización a nivel individual, intrahogar y, por lo tanto, relacional en cuanto a las preferencias, restricciones, libertades y oportunidades que los individuos presentan en el momento de la asignación de tiempo. Dicha asignación puede o no redundar en carencias de tiempo para sí mismo u otros miembros del hogar. Por ejemplo, un individuo podría no presentar carencia de tiempo dado que otro(s) miembro(s) de su hogar le ha transferido parte del suyo sacrificando o no su bienestar y, en consecuencia, esta transferencia podría ser considerada como solidaridad dentro del hogar.

El reconocimiento del tiempo como recurso, que puede ser afectado por factores de conversión (internos con relación al individuo, sociales o dentro del hogar), tiene una estrecha relación con el reconocimiento del cuidado, el TR y el ocio como capacidades. Dado que el tiempo es un recurso y un medio que visibiliza, junto con los factores de conversión, el nivel de influencia de la división sexual del trabajo y las expectativas y normas sociales asociadas a ella y, por cierto, el "nivel de agencia" que los individuos tienen para tomar decisiones diferentes a las expectativas sociales. Cabe destacar que no existe una lista definitiva que identifique las capacidades humanas. Sen (1992) deja abierta la definición de las capacidades e insiste en que estas deben ser definidas entre diferentes voces, con sensibilidad a las diferencias de género, dado que sería perjudicial para su definición que las capacidades fueran identificadas omitiendo estas diferencias. Por su parte, Nussbaum (2003) sostiene que se debiera desarrollar una lista de las capacidades básicas para el desarrollo humano. Es por ello que esta autora propone un listado de capacidades básicas y entre ellas entiende como una capacidad necesariamente universal el recibir y entregar cuidado.

El nivel de agencia individual (Sen, 2000) junto con la ausencia de autonomía de ingresos son causas, efectos o ambos de la interacción entre la pobreza del tiempo y las desigualdades a nivel individual, familiar y social. Un supuesto importante en el estudio de la pobreza del tiempo es considerar que los individuos con un mayor nivel de agencia tienen menos probabilidades de 
transitar o permanecer entre los individuos que presenten pobreza de tiempo. Sen (2000) define "agencia" como "un individuo que actúa y provoca cambios y cuyos logros pueden juzgarse en términos de sus propios valores y objetivos". En concordancia con el enfoque de capacidades, Pick y Sirkin (2010) plantean que los individuos que presentan un nivel de agencia más elevado asumen mayores libertades y responsabilidades, lo que incrementa el sentido de inversión personal en su desarrollo. Además, estas autoras caracterizan a un individuo que presenta agencia como una persona que no actúa según las expectativas y la evaluación externas. En consecuencia, un individuo con un menor nivel de agencia en un contexto de desigualdades en la distribución del tiempo probablemente presentará mayor carencia de tiempo en comparación con un individuo que ejerza un mayor nivel de agencia y que, por lo tanto, sea capaz de desvincular las expectativas y las evaluaciones externas con respecto a sus decisiones. Cabe preguntarse si esta desvinculación es un requisito o condición necesaria para el uso de las capacidades —definidas en términos de Sen-y para el ejercicio de la agencia.

Cuando un individuo se encuentra en un contexto de ausencia de justicia como resultado de restricciones externas o barreras estructurales, no está en condiciones de ejercer su autonomía económica. La falta de esta autonomía representa una privación de libertad cuando el individuo no puede, por ejemplo, dedicar su tiempo al TR, pues el TNR representa restricciones a la distribución del uso del tiempo. Por consiguiente, el TNR se transforma en una restricción o barrera de entrada al TR y al ejercicio de la libertad. Cuando los individuos no pueden ejercer su agencia y libertad, aumenta el efecto de los factores que limitan las posibilidades efectivas de las personas para superar la pobreza de tiempo. Desde la perspectiva de la CEPAL, la autonomía económica, la libertad y la justicia socioeconómica son componentes centrales del bienestar individual y social (CEPAL, 2014). La autonomía económica es una manifestación de la capacidad de ejercer la agencia individual en la distribución del tiempo entre actividades que pueden contribuir al bienestar. El concepto de libertad es parte de las nociones normativas respecto de las precondiciones que potencialmente garantizan que una persona ejerza su agencia.

\section{La pobreza de tiempo: consideraciones y supuestos sobre su definición}

La conceptualización de la pobreza del tiempo se ha desarrollado con mayor énfasis en el campo empírico que en el teórico. Más que una teoría comprensiva sobre este fenómeno existe un conjunto de supuestos que aún están en proceso de articulación y que se identifican a continuación.

En términos generales, la identificación de la población en situación de pobreza se basa en las condiciones socioeconómicas consideradas como inaceptables en una sociedad. Por una parte, la pobreza ha sido conceptualizada como la privación en el acceso a bienes, servicios e ingresos que permiten un nivel de bienestar aceptado como mínimo en una sociedad. Por otra, se le ha conceptualizado mediante la identificación de un grado inaceptable de inequidad en el contexto de los arreglos sociales (Sen, 1992).

En el desarrollo conceptual de la pobreza de tiempo se integran las nociones de igualdad, equidad, distribución, libertad y el reconocimiento de las injusticias dentro del hogar. Todas estas son nociones que en conjunto se consideran factores que explican parte de la asignación de tiempo entre las actividades que los individuos consideren valorables. La identificación de carencias — vinculadas a la inequidad intrahogar y en el mercado laboral- es una de las contribuciones del feminismo, que enfatiza en los efectos de la división sexual del trabajo y la excesiva carga laboral de las mujeres en la pobreza de tiempo. Las mujeres —además de trabajar de manera remunerada - son quienes contribuyen principalmente al TNR de los hogares (CEPAL, 2013c).

El primer supuesto, que es el más común en la literatura de pobreza de tiempo, es considerar el tiempo como un "recurso", así como las influencias negativas que las carencias de libertad y agencia de los individuos ejercen en la distribución del tiempo. Esta distribución es marcadamente influenciada por una desigual división del trabajo entre hombres y mujeres, y por la desvalorización social y económica de este tipo de trabajo en comparación con el remunerado (Jain, 2013, citado en CEPAL, 2013c).

Un segundo supuesto dice relación con el trade-off entre TR y TNR que existe a nivel individual y social. Cabe preguntarse si este se aplica a hombres y mujeres por igual, o más bien puede aplicarse a quienes valorizan de igual manera el TR y el TNR. Otro aspecto que cuestiona la existencia de este trade-off surge al preguntarse si es entre tiempo e ingresos.

En el tercer supuesto se sostiene que los individuos de la población con menor grado de poder dentro del hogar (Chiappori y otros, 2011), menor nivel de agencia individual (Pick y Sirkin, 2010) y menos poder sobre las decisiones respecto del gasto del hogar (Bonke y Browning, 2003), son quienes asignan una mayor proporción de su tiempo al TNR. En consecuencia, dichos factores restringirían una distribución equitativa del 
tiempo dedicado al TNR de un hogar entre sus miembros. Las restricciones asociadas a la "carencia de libertad en la asignación de tiempo" repercuten en las condiciones de vida de la población y en sus ingresos.

La asignación de tiempo al TR genera potencialmente recursos para satisfacer las necesidades de los individuos y sus familias que les permitan alcanzar la autonomía económica. La pobreza de tiempo afectaría de manera diferenciada al nivel de bienestar de la población dependiendo de su estatus económico. Es así como la pobreza de tiempo crea o intensifica la vulnerabilidad de los hogares no pobres de ingresos. Por ejemplo, los ocupados en los sectores de baja productividad y con menores ingresos, en comparación con sus pares, tendrían una mayor probabilidad de asignar más tiempo al TR con el objetivo de compensar sus bajos salarios. Y en consecuencia, estos ocupados dedicarían menos horas al TNR y al ocio, lo que afectaría su bienestar familiar y el de sus hogares.

En el cuarto supuesto se plantea que la pobreza de tiempo es una restricción al bienestar familiar y al desarrollo humano de los individuos. Vickery (1977) y Goodin y otros (2008) argumentan que además de los ingresos, un hogar requiere del tiempo necesario para mantener un nivel mínimo de producción - cuidado directo de dependientes menores y trabajo domésticopara su bienestar. Este supuesto es básico entre las mediciones de pobreza de tiempo, comprendiendo que un individuo y su hogar requieren no solo de ingresos para funcionar. En específico, el supuesto planteado desde el desarrollo empírico de los indicadores de bienestar plantea una relación positiva entre la "conciliación de la vida familiar y trabajo", entre otros criterios asociados a la calidad de vida.

El quinto supuesto se relaciona con el nivel de desigualdad en cuanto a la libre asignación de tiempo entre los grupos de ingreso de la población. En consecuencia, los estratos de menores ingresos presentarían un mayor nivel de restricción a sustituir el TNR mediante el consumo de trabajo doméstico en el mercado y parte del cuidado que es mercantilizado. Este tipo de ocupados tienen una alta probabilidad de presentar una carga excesiva de trabajo total (tiempo total en TR y TNR) y convertirse en "pobres de tiempo", y a la vez pertenecer al grupo vulnerable de ingreso. Es posible que los individuos de menores ingresos, por ejemplo, reciban transferencias de tiempo que compensen su carencia de acceso a servicios de cuidado provistos por el mercado y disminuyan su restricción de tiempo. Por lo que es necesario incorporar en las encuestas y módulos de las encuestas de hogares dedicados al uso del tiempo preguntas que permitan la identificación del origen y destino del TNR fuera de los hogares de quienes lo proveen.

El sexto supuesto se vincula con la heterogeneidad de necesidades que tienen los hogares para su funcionamiento, lo que se deriva de los ciclos que experimentan los hogares en cuanto a la producción de trabajo doméstico y cuidado, dependiendo de su composición (número de dependientes: niños y adultos mayores) y etapas del ciclo de vida de sus integrantes (Douthitt, 1994). El TNR centra su atención en la asignación de tiempo en el cuidado y el trabajo doméstico, y entre sus preguntas centrales con relación a la pobreza de tiempo y los ciclos de vida del hogar se encuentran: ¿cuál es el tiempo mínimo que podría asignarse al TNR para que el hogar funcione en sus distintos ciclos de vida?, y ¿cuál es la contribución relativa mínima al TNR que un individuo debe aportar en su hogar y que no presenta en sí misma una restricción de otros miembros de este en cuanto a su asignación de tiempo al TR y al ocio?

A diferencia de las mediciones de pobreza basadas en el enfoque de necesidades básicas, la pobreza de tiempo no solo se basa en la noción de acceso a mínimos sociales, sino que enfatiza en la falta de control o libertad sobre el uso de los recursos —en este caso el tiempo y los ingresos, o activos en la búsqueda de la satisfacción de las necesidades materiales (Goodin y otros, 2008 y Gammage, 2009). En cambio, las mediciones tradicionales de pobreza son una aproximación a las carencias materiales o de condiciones de vida. Y estas son representadas por la escasez y la precariedad de los recursos, los bienes o el acceso a servicios públicos (Feres y Mancero, 2001). Esta última aproximación a la pobreza es parte del marco conceptual en que se considera a los ingresos y los bienes materiales como las principales proxis del bienestar de la población.

Una de las preguntas clave para las mediciones y el análisis de la pobreza de tiempo es la siguiente: ¿se puede considerar a un individuo o a su hogar como pobre si sus decisiones en la asignación de tiempo han conducido a que presente un nivel más alto de bienestar económico condicionado a una mayor carencia de tiempo? Las respuestas a esta pregunta son probablemente divergentes, pero serían limitadas si solo se utilizan indicadores unidimensionales de pobreza de tiempo para informar un argumento que dé respuesta a esta pregunta. Responder a ella mediante indicadores que no solo utilicen el tiempo como variable es un desafío metodológico, pero también es necesario para una mejor comprensión de la pobreza y sus manifestaciones.

Durán (2007) agrega que la situación de pobreza de tiempo de los individuos es más transitoria que estructural, 
dado que el ciclo de vida de los individuos y sus hogares determina la mayor parte de su pobreza de tiempo. Con este supuesto se asume que, en la etapa del ciclo de vida en que los menores dependientes de cuidados directos transitan a una etapa de cuidado indirecto, sus padres podrían liberar de manera equitativa el tiempo que antes dedicaban a cuidados directos. Comprendiendo que el ejemplo anterior está determinado en gran parte por los roles de género, Durán (2007) releva la importancia de visibilizar de qué manera estos roles rigidizan la distribución de tiempo entre las mujeres y los hombres. La cercanía o distancia de las decisiones y comportamientos de los individuos con respecto a estos roles determina en parte el nivel de libertad y flexibilidad en la asignación de tiempo entre el TR, el TNR, las actividades personales y el tiempo libre destinado al ocio. $\mathrm{Al}$ reconocer que parte de esta rigidez en la asignación de tiempo se vincula a los roles de género, afectando y ajustando la elección de potenciales funcionamientos alternativos a las expectativas sociales, un indicador de pobreza de tiempo podría representar la noción de justicia distributiva. El énfasis y la ventaja de articular una definición de pobreza de tiempo desde el enfoque de género y capacidades radican en que si un individuo presenta carencia de tiempo, esta podría ser entendida como una restricción a elección de los individuos entre distintas combinaciones de actividades que impactan en la asignación de tiempo, lo que podría mermar el bienestar individual.

Gran parte de los indicadores de pobreza de tiempo han visibilizado brechas, tendencias o cambios en los niveles de los fenómenos que estudian y, específicamente, han medido los funcionamientos o resultados en lugar de las capacidades. Es así como, por ejemplo, la carencia de capacidad para la vida sana y buena nutrición es considerada por igual entre los individuos que no tienen la capacidad de una buena nutrición como también en aquellos que ayunan por una decisión libre e informada basada en sus propias preferencias. Este ejemplo, aplicado a la pobreza de tiempo como una restricción a las capacidades, recuerda la complejidad de identificar a un sujeto como pobre de tiempo sin conocer sus preferencias o al menos su intención en un escenario imaginario de cambiar la distribución de tiempo. Lo anterior es asumir el desafío de incluir preguntas relativas a preferencias y expectativas en cuanto a la distribución actual y redistribución futura del uso del tiempo de la población.

Las mediciones de pobreza de tiempo pueden agruparse en unidimensionales y bidimensionales. El principal objetivo de los estudios unidimensionales es la identificación del déficit de tiempo que los individuos enfrentan luego de la asignación cronológica a sus actividades de TR y TNR y su relación con la pobreza de ingresos de esta población privada de tiempo discrecional (Goodin y otros, 2008). En cambio, el propósito de los estudios de la pobreza de tiempo a nivel bidimensional es identificar a la población en situación de dicha pobreza condicional a sus carencias de tiempo e ingresos (Zacharias, 2011). Según las autoras del presente trabajo, las mediciones bidimensionales de pobreza de tiempo e ingresos padecen de una limitación importante: la perspectiva de género se supedita exclusivamente a la desagregación por sexo de los indicadores. Por esta razón, se considera que las mediciones bidimensionales de pobreza de tiempo e ingreso se ven limitadas para una comprensión más profunda de las desigualdades y la carencia de justicia en cuanto al reconocimiento y valorización de la contribución de las mujeres al trabajo no remunerado en los hogares.

En la siguiente sección se desarrolla un indicador multidimensional utilizando los supuestos identificados en la literatura de pobreza del tiempo. Se estima que las dimensiones de dicho indicador son "espacios" en los que los individuos pueden ejercer su libertad y su agencia durante los procesos de distribución entre TR y TNR. De la revisión de los marcos conceptuales realizada en esta sección, el enfoque de capacidades contribuye a responder de qué modo es posible evidenciar, mediante un indicador multidimensional, los obstáculos a nivel individual e intrahogar que disminuyen la libertad y equidad entre sus miembros y determinar en qué casos la distribución del uso de tiempo es un asunto de ausencia de justicia. Por otra parte, usar la teoría de la justicia en el marco del enfoque de capacidades implica que la justicia y la aproximación a ella mediante el desarrollo de un indicador multidimensional deben ser sensibles a la habilidad de los individuos para transformar sus capacidades en funcionamientos efectivos. 


\section{III}

\section{Metodología del indicador de bienestar}

\section{Descripción de los datos: encuestas sobre uso del tiempo}

Las fuentes de datos son las encuestas sobre uso del tiempo de cuatro países de la región: Colombia (2012), el Ecuador (2012), México (2009) y el Uruguay (2007), que corresponden a las encuestas sobre el uso del tiempo (EUT) disponibles en el momento de la investigación. En el cuadro 1 se resume la información metodológica de dichas encuestas.

Las mujeres trabajan más que los hombres: en promedio para los cuatro países, el tiempo total de trabajo es de 45,9 horas semanales para los hombres y de 52,5 horas para las mujeres (véase el gráfico 1). Al desglosar por tipo de trabajo, se evidencia su división sexual: el nivel de TNR de las mujeres es tres veces superior al de los hombres. Además, existe heterogeneidad en el nivel de TNR (cuidado y trabajo doméstico) para las mujeres y homogeneidad para los hombres (controlando por nivel de educación, de ingreso, de estado civil, presencia de dependientes en el hogar, condición de actividad y de edad).

El ciclo de vida de los individuos constituye otro elemento importante en el análisis: es durante el tramo de edad de 25 a 45 años que hombres y mujeres trabajan más tiempo. Es también en ese tramo que se dan las mayores brechas entre hombres y mujeres (véase el gráfico 2).

CUADRO 1

Descripción de las encuestas sobre uso del tiempo (EUT)

\begin{tabular}{|c|c|c|c|c|}
\hline País/año & Objetivo y universo & Clasificador & $\begin{array}{l}\text { Tamaño muestral } \\
\text { y cobertura }\end{array}$ & Aspectos metodológicos \\
\hline Colombia (2012) & $\begin{array}{l}\text { Generar información sobre el tiempo } \\
\text { dedicado por la población de } 10 \text { años y } \\
\text { más a actividades de trabajo y personales }\end{array}$ & $\begin{array}{l}\text { CAUTAL } \\
\text { ICATUS }\end{array}$ & $\begin{array}{c}46310 \text { hogares } \\
\text { Nacional }\end{array}$ & $\begin{array}{l}\text { Lista de actividades } \\
24 \text { horas antes de la } \\
\text { entrevista }\end{array}$ \\
\hline Ecuador (2012) & $\begin{array}{l}\text { Generar información sobre la distribución } \\
\text { del tiempo en actividades remuneradas, no } \\
\text { remuneradas y de tiempo libre que realizan } \\
\text { individuos (de } 12 \text { años y más) }\end{array}$ & CAUTAL & $\begin{array}{c}23400 \text { hogares } \\
\text { Nacional }\end{array}$ & $\begin{array}{l}\text { Lista de actividades } \\
\text { Semana }\end{array}$ \\
\hline México (2009) & $\begin{array}{l}\text { Medir el tiempo destinado por las personas } \\
\text { (de } 12 \text { años y más) a sus actividades diarias } \\
\text { y proporcionar los insumos estadísticos } \\
\text { necesarios para la medición de todas las } \\
\text { formas de trabajo de las personas, incluido } \\
\text { el remunerado y no remunerado }\end{array}$ & $\begin{array}{l}\text { CMAUT } \\
\text { ICATUS }\end{array}$ & $\begin{array}{c}16925 \text { hogares } \\
\text { Nacional }\end{array}$ & $\begin{array}{l}\text { Lista de actividades } \\
\text { Semana }\end{array}$ \\
\hline Uruguay (2007) & $\begin{array}{l}\text { Proporcionar información sobre la } \\
\text { participación y el tiempo que los miembros } \\
\text { de los hogares, mujeres y hombres, de } 14 \\
\text { años y más, dedican a las actividades no } \\
\text { remuneradas y a los diferentes tipos de } \\
\text { trabajo no remunerado }\end{array}$ & ICATUS & $\begin{array}{l}4200 \text { hogares } \\
\text { Nacional }\end{array}$ & $\begin{array}{l}\text { Lista de actividades } \\
\text { Semana }\end{array}$ \\
\hline
\end{tabular}

Fuente: Elaboración propia sobre la base de información oficial.

Nota: CMAUT: Clasificación Méxicana de Actividades de Uso del Tiempo; ICATUS: International Classification of Activities for Time Use Statistics; CaUtal: Clasificación de actividades de uso del tiempo para América Latina. 
GRÁFICO 1

Colombia, Ecuador, México y Uruguay: tiempo destinado al TR y al TNR. Población de 15 años y más y población ocupada

(En horas semanales)

A. Población de 15 años y más

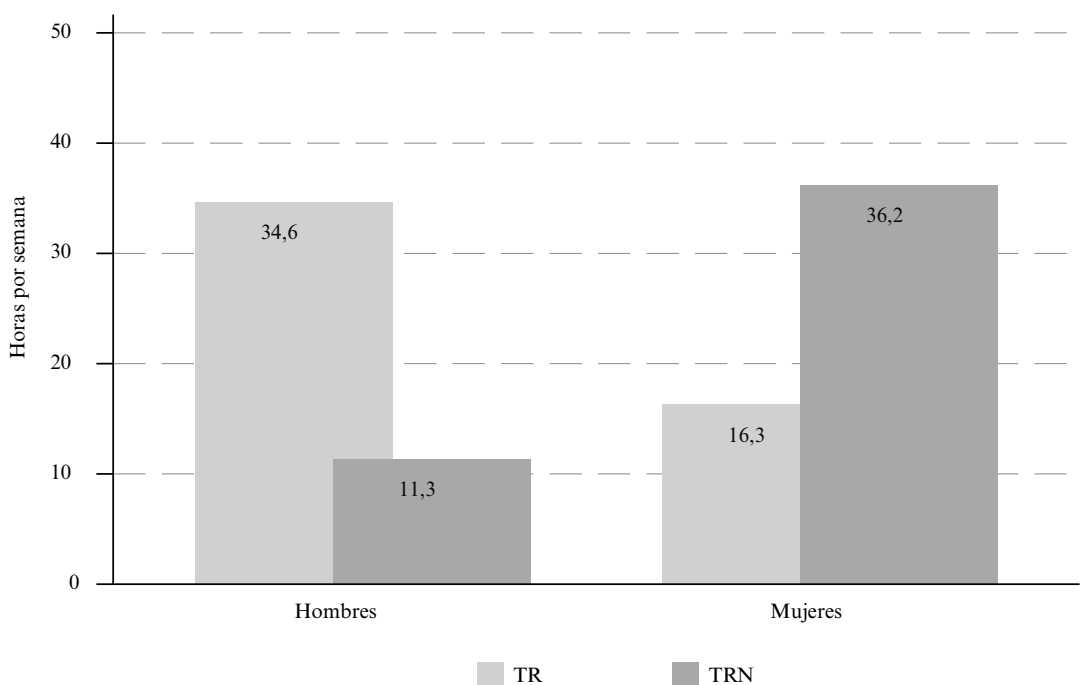

B. Población ocupada

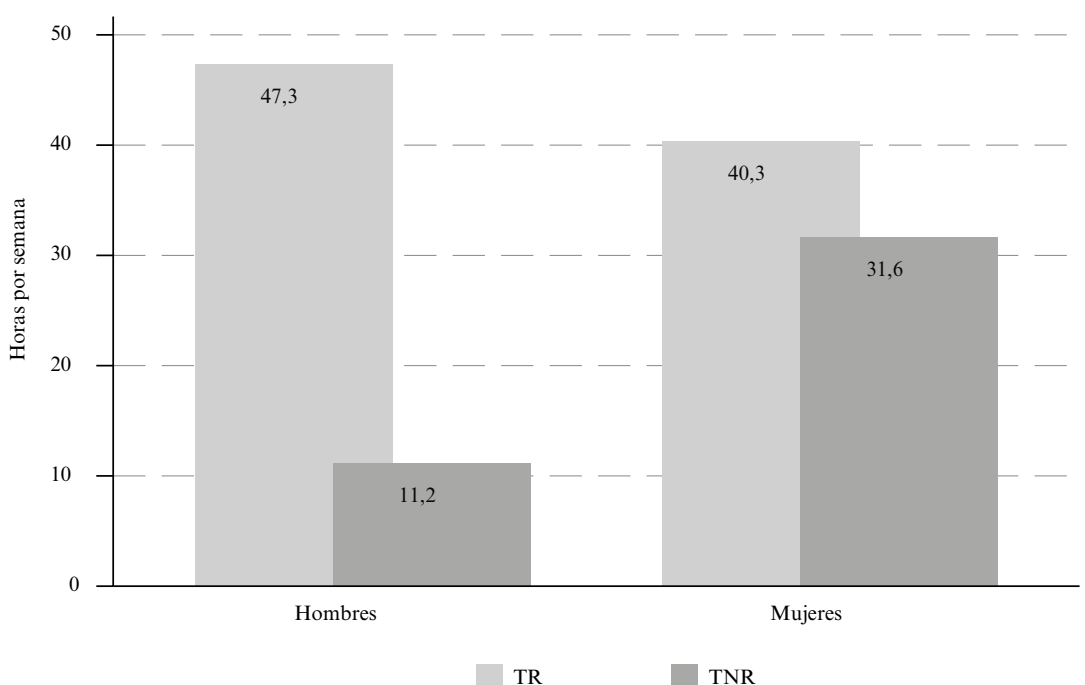

Fuente: Elaboración propia sobre la base de tabulaciones de las encuestas sobre uso del tiempo (EUT) de Colombia (2012), el Ecuador (2012), México (2009) y el Uruguay (2007).

Nota: Promedios simples; TR: Trabajo remunerado; TNR: Trabajo no remunerado. 
GRÁFICO 2

Colombia, Ecuador, México y Uruguay: tiempo destinado al TR y al TNR según tramos de edad. Población de 15 años y más

(En horas semanales)

A. Trabajo remunerado

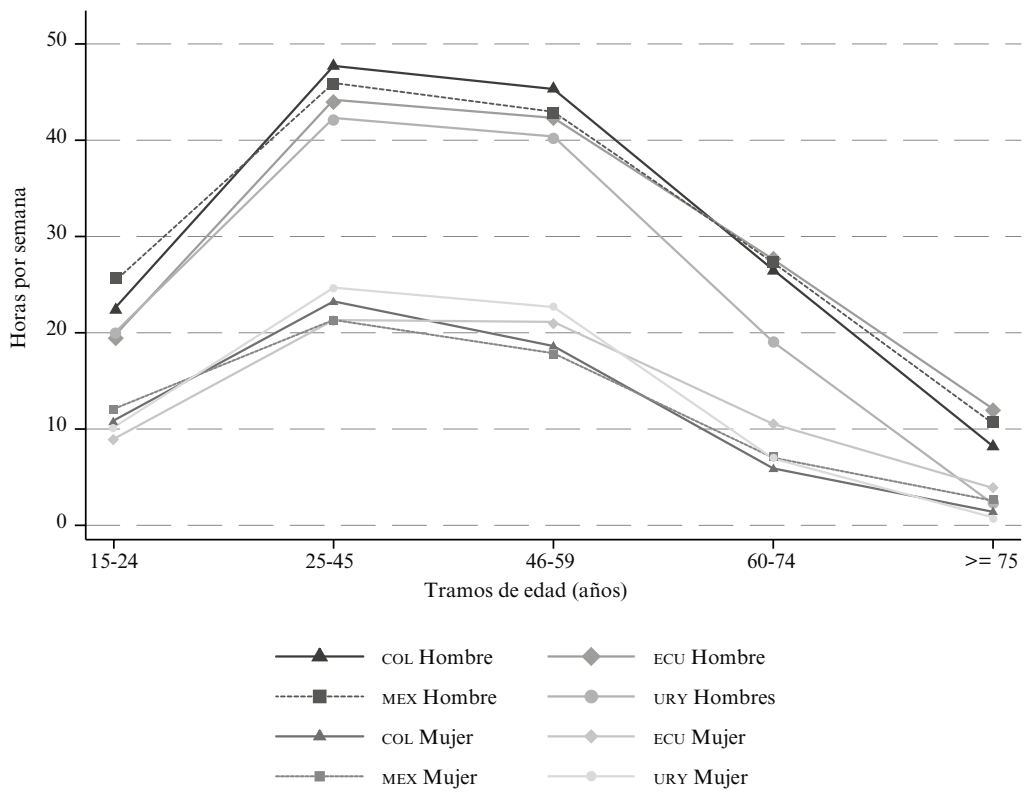

B. Trabajo no remunerado

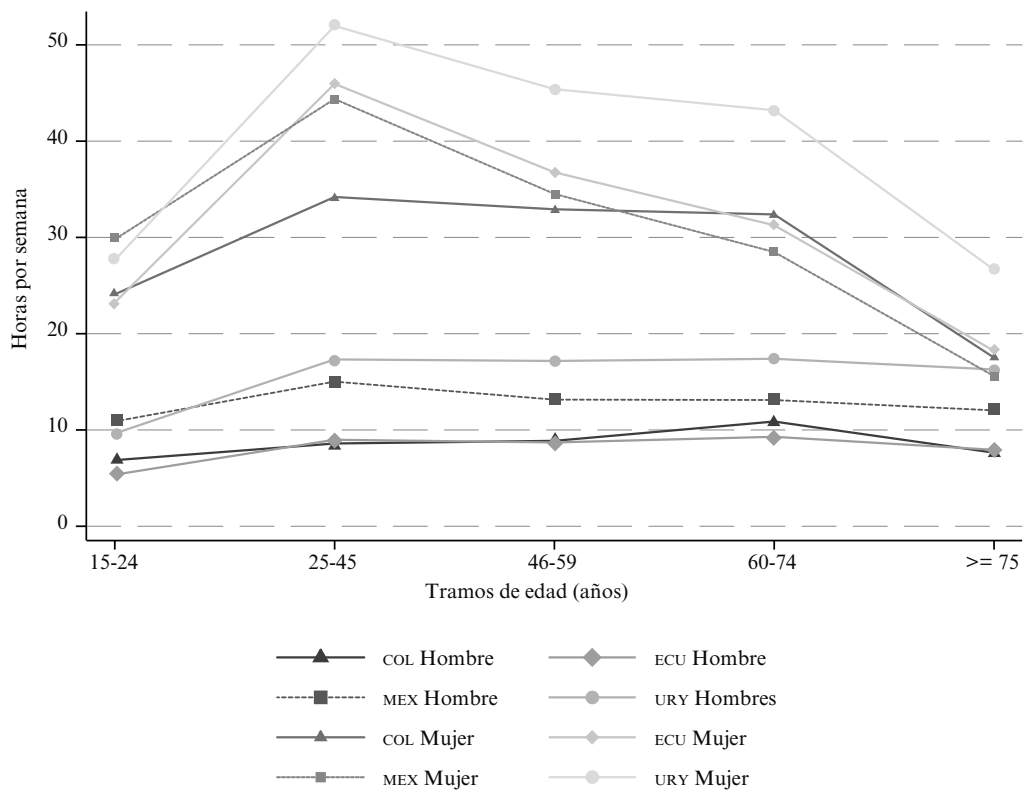

Fuente: Elaboración propia sobre la base de tabulaciones de las encuestas sobre uso del tiempo (EUT) de Colombia (2012), el Ecuador (2012), México (2009) y el Uruguay (2007).

Nota: COL: Colombia; ECU: Ecuador; MEX: México; URY: Uruguay; TR: Trabajo remunerado; TNR: Trabajo no remunerado. 
Estos hallazgos han sido ampliamente reportados en diferentes estudios (véase CEPAL, 2010a, 2010b y 2013c; Merino, 2010 y 2012). En este artículo se da un paso más en el análisis al centrar la mirada en el interior de los hogares y observar cómo se distribuye el tiempo de TNR entre sus integrantes. En el gráfico 3 se evidencia el aporte porcentual de hombres y mujeres al TNR dentro del hogar. Para la población total (panel izquierdo de la sección A del gráfico 3), en promedio, el hombre (jefe de hogar o cónyuge) contribuye con el $22 \%$ del tiempo total del TNR de su hogar, mientras la mujer (jefa de hogar o cónyuge) aporta el 57\% del TNR. El remanente, es decir, el $22 \%$ del tiempo total del TNR del hogar, es realizado por otros integrantes (hijos, otros familiares $\mathrm{u}$ otros adultos). Estas proporciones varían en una magnitud muy pequeña según la condición de actividad (paneles del centro y derecha de la sección A del gráfico 3). Si se observa el aporte porcentual según el tipo de hogar, la brecha entre hombres y mujeres es más amplia en el caso de los hogares biparentales: mientras las mujeres contribuyen en promedio con el 64\% del TNR del hogar, los hombres solo contribuyen con un 18\% (panel del centro de la sección B del gráfico 3). En el caso de los hogares compuestos y extendidos (panel izquierdo de la sección B del gráfico 3), la contribución de hombres y mujeres es menor, poniendo en evidencia la contribución de los otros miembros del hogar. Finalmente, cabe destacar el caso de los hogares monoparentales (panel derecho de la sección B del gráfico 3): el único en que los hombres contribuyen más que las mujeres ${ }^{9}$.

\footnotetext{
${ }^{9}$ Es necesario considerar que solo un $11,3 \%$ de los hombres son jefes de hogar monoparentales, mientras que el $31,4 \%$ de las mujeres se encuentran en esa condición.
}

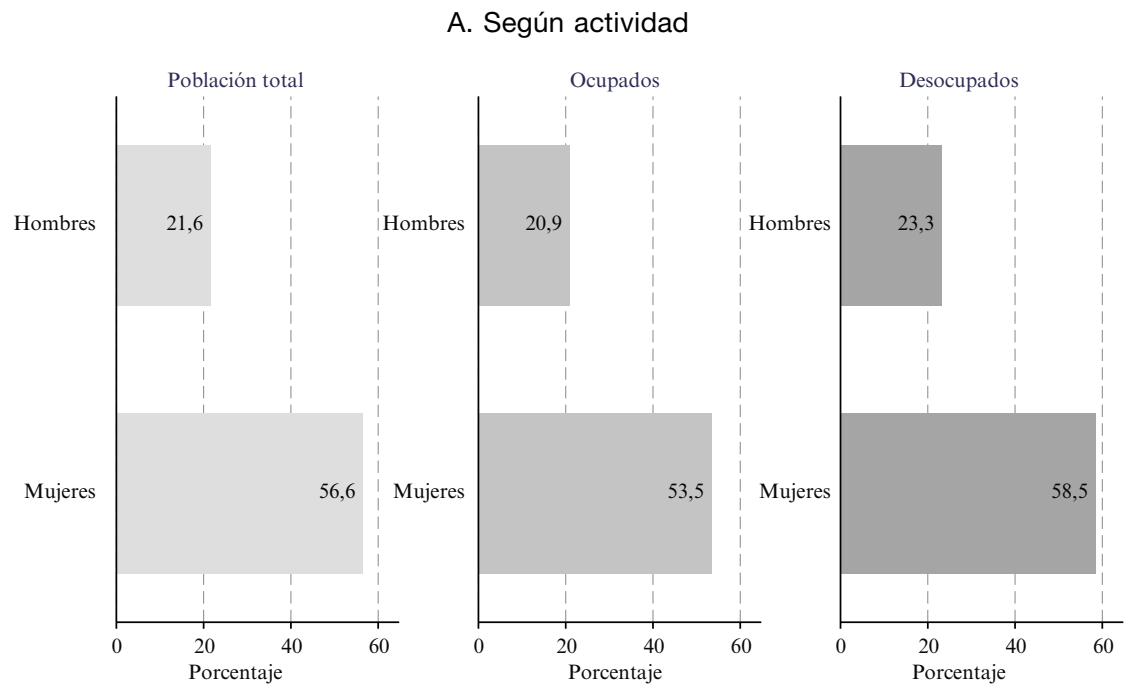




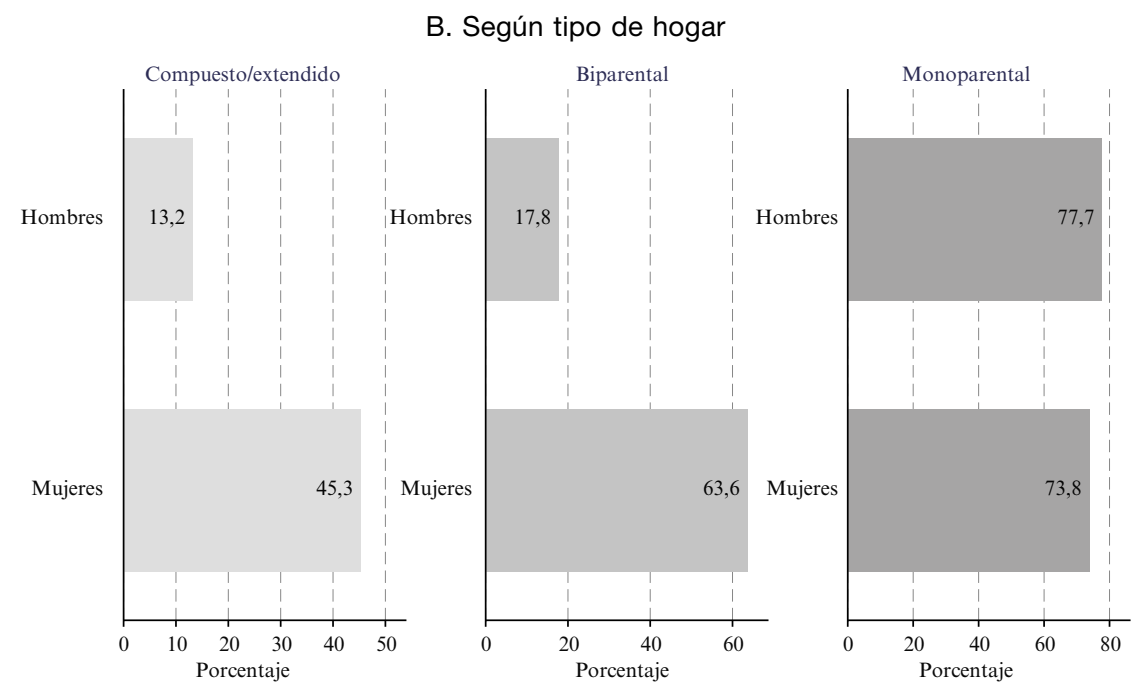

Fuente: Elaboración propia sobre la base de tabulaciones de las encuestas sobre uso del tiempo (EUT) de Colombia (2012), el Ecuador (2012), México (2009) y el Uruguay (2007).

Nota: El trabajo no remunerado (TNR) corresponde a las horas promedio de trabajo doméstico, cuidado y trabajo voluntario. En las cuatro encuestas consideradas, las entrevistas son realizadas a todos los miembros del hogar de más de 10, 12 o 14 años según el país (véase el cuadro 1).

\section{Definición de la unidad de análisis: los hogares}

Los individuos no solo comparten el mismo techo y sus ingresos (independientemente de que estos se distribuyan de manera igualitaria), sino también el tiempo y su distribución dentro del hogar. A excepción de los hogares unipersonales, los individuos no distribuyen su tiempo de manera independiente de los demás integrantes del hogar. Existe un debate en el interior del pensamiento feminista contemporáneo en que se cuestiona la autodeterminación como una noción que define la distribución del tiempo, porque la autodeterminación sería comprendida como una noción relacional y grupal. Dicho de otro modo, la idea de un hombre o una mujer que ejerce su autodeterminación luego de un proceso de reflexión y priorización de preferencias es entendida en un contexto de relaciones entre los individuos.

Las desigualdades en la distribución del tiempo ya evidenciadas en el TR y el TNR entre hombres y mujeres no solo se entienden desde la perspectiva de género, también se relacionan con la composición y estructura de los hogares, y el ciclo de vida a nivel familiar e individual. La carga excesiva de TR y TNR tiene un componente estructural y transitorio desde la perspectiva de los hogares. Por consiguiente, el análisis debe hacerse desde esa unidad porque los miembros de un hogar tienen distintas capacidades interrelacionadas con decisiones individuales y relacionales en la asignación de su tiempo.

Definir a los hogares como unidad de análisis implica considerar la interrelación entre sus miembros como un aspecto clave en la distribución y valorización del trabajo remunerado y no remunerado dentro de un hogar. Esto permite considerar al hogar como un espacio donde se desarrollan actividades económicas y como extensión del mercado laboral más que considerarlo como un espacio antagónico al mercado.

En este estudio también se propone realizar un análisis según tipo de hogares (tamaño y composición) para poner atención en los patrones demográficos de los países que pueden afectar a las medidas de pobreza multidimensional. Cabe señalar que definir a los hogares como unidad de análisis no producirá una subestimación de la incidencia de la pobreza de tiempo y condiciones de vida, ya que "por construcción, la privación multidimensional a nivel individual siempre representa menos pobreza que las medidas multidimensionales y las privaciones del hogar" (Díaz, 2013).

En lo que sigue del capítulo se analizarán los hogares usando la siguiente tipología: i) nuclear biparentales; ii) monoparentales; iii) unipersonales; iv) compuestos y extendidos con dos adultos significativos (cónyuges y jefe(a) de hogar), y v) otros compuestos y extendidos. En todos los hogares se excluye a las personas que realizan 
los trabajos domésticos de manera remunerada y a sus dependientes. La tipología antes mencionada se basa en aquella definida por la División de Estadísticas de las Naciones Unidas ${ }^{10}$, con algunas modificaciones acordes con esta investigación, es decir, se juntan los hogares compuestos y extendidos y se separan en dos grupos en función de la presencia de cónyuges en el hogar.

\section{Definición de las dimensiones y sus indicadores}

El indicador propuesto incluye cinco dimensiones: uso del tiempo, condiciones de vida, autonomía económica, educación y exclusión social. Los indicadores más empleados en las mediciones multidimensionales de

10 Véase el enlace http://unstats.un.org/unsd/demographic/sconcerns/ fam/fammethods.htm. pobreza son los que captan carencias en la vivienda (hacinamiento y materialidad), en los servicios básicos (agua, saneamiento y energía) y en la educación por su relevancia y también por la disponibilidad de información en las encuestas de hogares. Aquí se recoge lo propuesto por la CEPAL (2013b) en cuanto a esas dimensiones usuales y se agregan las dimensiones referidas a tiempo y autonomía económica. En el cuadro 2 se definen las dimensiones, los indicadores y los ponderadores que integran el indicador multidimensional.

La dimensión "uso del tiempo" se compone de dos indicadores: uno referido al TNR y otro al TR.

Indicador 1: el tiempo para el TNR, que incluye el trabajo doméstico y el cuidado de otros. El hogar es carente si al menos uno de sus integrantes presenta una contribución individual (en porcentaje) al TNR del hogar inferior al 50\% de la mediana población femenina de 15 años y más (la mediana de la contribución calculada por tipo de hogar).

CUADRO 2

\section{Dimensiones e indicadores de carencias y ponderaciones}

\begin{tabular}{|c|c|c|}
\hline Variables & $\begin{array}{l}\text { Indicador de carencia: } \\
\text { el hogar presenta una privación si al menos un integrante del hogar... }\end{array}$ & Ponderadores \\
\hline Dimensión I: tiempo & & $1 / 5$ \\
\hline Tiempo para trabajo no remunerado & $\begin{array}{l}\text { Contribución porcentual individual al TNR (cuidado + trabajo doméstico) } \\
\text { inferior al } 50 \% \text { de la mediada de la contribución de las mujeres, según tipo } \\
\text { de hogar }\end{array}$ & $1 / 10$ \\
\hline Tiempo para trabajo remunerado & $\begin{array}{l}\text { Número de horas superior al máximo semanal de acuerdo con la legislación } \\
\text { nacional }\end{array}$ & $1 / 10$ \\
\hline Dimensión II: condiciones de vida & & $1 / 5$ \\
\hline $\begin{array}{l}\text { Carencia de acceso a fuentes de agua } \\
\text { mejorada }\end{array}$ & $\begin{array}{l}\text { Áreas urbanas: cualquier fuente de agua excepto red pública } \\
\text { Áreas rurales: pozo no protegido, agua embotellada, fuente de agua móvil, } \\
\text { quebrada, río, lluvia, otros }\end{array}$ & $1 / 30$ \\
\hline $\begin{array}{l}\text { Carencia de sistema de eliminación de } \\
\text { excretas }\end{array}$ & $\begin{array}{l}\text { No disponer de servicio higiénico o de un sistema de evacuación conectado } \\
\text { a red de alcantarillado o fosa séptica }\end{array}$ & $1 / 30$ \\
\hline Carencia de energía eléctrica & Hogares no tienen electricidad & $1 / 30$ \\
\hline $\begin{array}{l}\text { Combustible para cocinar riesgoso para } \\
\text { la salud }\end{array}$ & Hogares que usan leña, carbón o desechos para cocinar & $1 / 30$ \\
\hline Precariedad de materiales de la vivienda & $\begin{array}{l}\text { La mayor parte de la vivienda es de material precario } \\
\text { La mayor parte del techo es de material precario } \\
\text { El piso es de tierra }\end{array}$ & $1 / 30$ \\
\hline Hacinamiento & Número de personas por cuarto para dormir es mayor o igual a tres & $1 / 30$ \\
\hline Dimensión III: autonomía económica & & $1 / 5$ \\
\hline Ingresos laborales & $\begin{array}{l}\text { Salario diario inferior a dos veces el salario diario mínimo }(53,19 \text { pesos } \\
\text { mexicanos) }\end{array}$ & $1 / 10$ \\
\hline Población sin ingresos propios & $\begin{array}{l}\text { Al menos un individuo (no estudiante de } 15 \text { años y más) no cuenta con } \\
\text { ingresos propios }\end{array}$ & $1 / 10$ \\
\hline
\end{tabular}


Cuadro 2 (conclusión)

Variables

Indicador de carencia:

el hogar presenta una privación si al menos un integrante del hogar...

Ponderadores

\begin{tabular}{ll}
\hline Dimensión IV: educación & \\
\hline Inasistencia a la escuela & Al menos un niño en edad escolar (6 a 17 años) no asiste a la escuela \\
Rezago educacional de los adultos & $\begin{array}{l}\text { Al menos un adulto de } 30 \text { años y más no cuenta con un nivel educativo } \\
\text { mínimo }\end{array}$ \\
$\begin{array}{l}\text { Individuos de } 30 \text { a } 59 \text { años: no cuentan con educación básica completa o } \\
\text { sin educación } \\
\text { Individuos de } 60 \text { años y más: no cuentan con educación }\end{array}$
\end{tabular}

Dimensión V: exclusión social o vulnerabilidad

$1 / 5$

Ni-ni (no trabaja, ni estudia)

Población entre 18 y 29 años que no trabaja ni estudia (desempleados +

$1 / 10$

Acceso a salud

Individuos en el hogar sin acceso al sistema de salud nacional

$1 / 10$

Fuente: Elaboración propia.

Incluir un indicador asociado a la asignación de tiempo para el TNR en un indicador de bienestar multidimensional tiene como objetivo visibilizar las contribuciones individuales al trabajo total del hogar en cuidado y trabajo doméstico intrahogar desde una perspectiva de género, porque permite identificar la división sexual del trabajo dentro del hogar. En consecuencia, en el indicador propuesto se incorpora la perspectiva de género en su concepción misma y no por la desagregación por sexo. Otro argumento en favor de este indicador es que incluye un componente de justicia social al distinguir las contribuciones individuales al cuidado y el trabajo doméstico de los adultos significativos del hogar —cónyuges y jefes o jefas de hogar- de sus otros miembros en el interior del hogar. El análisis estadístico de los componentes de este indicador determinó que para cada uno los subumbrales - según los tipos de hogar- el 50\% de la mediana del tiempo asignado al cuidado y trabajo doméstico de las mujeres sea considerado como el umbral del indicador que distingue entre los hogares carentes y no carentes. Es entonces un umbral relativo.

Este indicador contribuirá a la identificación de la población y los hogares donde existieren menores oportunidades e igualdad de género para el ejercicio de las capacidades de cuidado y TNR.

La identificación de un mínimo de asignación de tiempo al TNR se basa en un hecho que representa una de las restricciones al desarrollo de las capacidades de las mujeres, y es condicional "al desproporcionado aporte de las mujeres al trabajo no remunerado" (ONUMujeres, s/f). En ese contexto, identificar el sector de la población que es carente en TNR resulta crucial en orden de evidenciar la desigualdad de género dentro del hogar.
Con el objetivo de reconocer las diferencias entre los tipos de hogares en cuanto a su estructura y su potencial redistribución del TNR entre sus miembros, se incorporan subumbrales por tipo de TNR (trabajo doméstico y cuidado) y por tipo de hogar. Burchardt (2010) argumenta que en el caso del trabajo doméstico es posible establecer un mínimo de asignación de tiempo absoluto a este tipo de trabajo, el que estaría basado en las necesidades domésticas de un hogar dependiendo de su composición. Sin embargo, en este estudio no se utiliza este tipo de indicadores, porque dada la heterogeneidad de tipos de hogares y aun cuando es posible identificar umbrales para cada tipo de hogar (según su composición), definir un umbral absoluto requiere de un alto nivel de debate y acuerdos en torno de cuál es el tiempo mínimo de TNR que los hogares requieren para su funcionamiento.

Por ejemplo, a modo de ilustración para el caso de México, en los hogares nucleares biparentales, el 51,7\% de estos presentan al menos un individuo con carencias asociadas al cuidado y trabajo domésticos (véase el cuadro 3). Se considera carente un hogar si cumple al menos una de las siguientes condiciones: i) el jefe(a) de hogar o cónyuge contribuye con menos del $38,5 \%$ en trabajo doméstico y menos del $24,1 \%$ en cuidado al total del tiempo asignado en su hogar a ambos componentes del trabajo no remunerado, o ii) los otros integrantes del hogar ${ }^{11}$ presentan contribuciones inferiores a un $8,2 \%$ y un $9,3 \%$ al total del tiempo asignado en su hogar al trabajo doméstico y cuidado del hogar, respectivamente.

\footnotetext{
11 Integrantes distintos del jefe(a) de hogar o cónyuge, excluidos los dependientes mayores de 80 años.
} 
México: valor de los subumbrales según tipo de hogar y grupos intrahogar, y tasa de recuento de hogares carentes según el indicador 1

\begin{tabular}{llcc}
\hline Tipo de hogar & Grupos dentro del hogar & $\begin{array}{c}\text { Valor del punto de } \\
\text { corte-contribución } \\
\text { porcentual individual al } \\
\text { trabajo doméstico }\end{array}$ & $\begin{array}{c}\text { Valor del punto de } \\
\text { corte-contribución } \\
\text { porcentual individual al } \\
\text { cuidado } \\
\text { ambos componentes } \\
\text { del indicador según } \\
\text { tipos de hogar } \\
(\text { en porcentajes })\end{array}$ \\
\hline Unipersonal & Jefe de hogar y/o cónyuge & 50,0 & $\ldots$ \\
\hline Compuesto o extendido & Jefe de hogar y/o cónyuge & 24,6 & 11,4 \\
& Otros integrantes del hogar & 10,7 & 10,0 \\
\hline Biparental & Jefe de hogar y/o cónyuge & 38,5 & 24,1 \\
\hline Monoparental & Otros integrantes del hogar & 8,2 & 9,3 \\
\hline Compuesto o extendido & Jefe de hogar y/o cónyuge & 40,5 & 25,0 \\
sin cónyuge & Otros integrantes del hogar & 14,1 & 16,1 \\
\hline
\end{tabular}

Fuente: Elaboración propia sobre la base de tabulaciones de la encuesta sobre uso del tiempo (EUT) de México, 2009.

Indicador 2: carencia de tiempo relativa a la sobrecarga o exceso de trabajo remunerado (TR) de acuerdo con la legislación nacional. Un hogar es considerado carente si al menos uno de sus integrantes ocupados dedica un número total de TR superior al número máximo de horas — definido por la legislación- de TR.

Cabe señalar que antes de definir este umbral de carácter normativo, se probaron varios puntos de corte de naturaleza relativa basados en la distribución estadística de los datos entre la población relevante para este indicador. De este modo, se estimó la mediana de tiempo de TR de los ocupados de 15 años y más y se utilizó el $75 \%$ de esta mediana con el objetivo de definir un umbral mínimo de tiempo que debiera asignarse al TR.

Este indicador define la carencia de tiempo para el TR en términos normativos: un hogar es considerado carente de tiempo debido a su carga excesiva de TR cuando al menos uno de sus integrantes asigna a este un tiempo superior a las horas semanales según la legislación del país. Un carga excesiva de TR, de acuerdo con la legislación mexicana, implica que un ocupado trabaja más de 57 horas semanales (OIT, 2013). Entonces, si al menos uno de los adultos significativos o adultos no dependientes de un hogar trabaja más de 11,4 horas diarias en promedio, este hogar será considerado carente de tiempo. Cabe mencionar que el $52 \%$ de los individuos que presentan carencia de TR, también presentan carencia para el TNR.

Una pregunta central se refiere a cuál es la proporción de trabajadores reenumerados que excede el máximo de horas legales y que recibe como ingresos laborales una cantidad igual o menor a dos salarios mínimos (este último es uno de los indicadores de la dimensión "autonomía económica"). En el caso de México, el 38\% de la población ocupada trabaja más horas que el máximo legal y recibe un salario igual o menor de dos salarios mínimos. Por lo tanto, la situación de los ocupados en cuanto a sus ingresos y tiempo de TR es bastante distinta a la planteada en la literatura, la que se concentra en las largas horas de trabajo de los trabajadores de elevados ingresos (Warren, 2003). Por el contrario, este 38\% de la población ocupada trabaja de manera remunerada una larga jornada laboral y sus ingresos no los ubicarían en la parte media de la distribución de ingresos de la población ocupada.

Un umbral alternativo posible consiste en considerar como carentes a los hogares donde al menos uno de sus integrantes ocupados (de 15 años y más) trabaje un total de horas semanales inferior al $75 \%$ de la mediana de horas de TR de los ocupados. Usar un punto de corte de $100 \%$ de la mediana duplica el porcentaje de individuos con esta carencia. Este umbral alternativo se desestimó dado que durante el proceso de presentación y debate de este indicador fue complejo acordar la implicancia de política de un indicador de pobreza de tiempo para el TR basado en un mínimo.

El desarrollo del resto de los componentes del indicador multidimensional se basa en el capítulo 1 del Panorama Social de América Latina 2013 (CEPAL, 2013b), según el cual la pobreza multidimensional se construye a partir de seis dimensiones (Agua y 
saneamiento, Energía, Vivienda, Educación, Ingresos, Exclusión). La propuesta del presente trabajo sigue esos lineamientos con dos excepciones. Primero, se agrupan en una misma dimensión todos los aspectos relacionados con las condiciones de la vivienda: agua, saneamiento, energía y materialidad y hacinamiento. Segundo, en lo que se refiere a ingresos, estos se analizan en función del concepto de "autonomía económica", definida como "la capacidad de las mujeres de generar ingresos y recursos propios a partir del acceso al trabajo remunerado en igualdad de condiciones que los hombres, considerando el uso del tiempo y la contribución de las mujeres a la economía". Esto da cuenta del concepto más general de libertad, factor fundamental para garantizar el ejercicio de derechos humanos de las mujeres en un contexto de plena igualdad. La identificación de los hogares en los que al menos uno de sus integrantes (excluidos los dependientes) carece de autonomía económica es de crucial importancia, porque permite la inclusión de una dimensión decisiva para el potencial desarrollo de otras capacidades. Es parte del objetivo de esta dimensión remarcar que, por debajo de un nivel mínimo de autonomía económica, es probable que un individuo enfrente restricciones al desarrollo de otras capacidades como consecuencia de las limitaciones que presenta la carencia de autonomía económica mínima.

La dimensión "autonomía económica” incluye dos indicadores:

Indicador 1: ingresos laborales. Un hogar es considerado carente si al menos uno de sus miembros tiene un salario diario inferior a dos veces el salario diario mínimo legal (en el caso de México: 53,19 pesos mexicanos) $)^{12}$.

Indicador 2: población sin ingresos propios. Un hogar es considerado carente si al menos un individuo mayor (de 30 años o más de edad) —excluidos los estudiantes y los dependientes mayores de 80 años y discapacitados permanentes — no posee ingresos propios provenientes de un trabajo remunerado.

12 Salario mínimo diario promedio vigente al año 2009. Información provista por la Secretaría del Trabajo y Previsión Social.

\section{IV}

\section{Resultados de las estimaciones Incidencia, intensidad y $\mathbf{M}_{0}$}

A continuación se presentan los resultados del indicador multidimensional de tiempo y condiciones de vida para Colombia (2012), el Ecuador (2012), México (2009) y el Uruguay (2007).

En el gráfico 4 se muestra la tasa de recuento bruta por indicador. En la dimensión tiempo: entre el $45 \%$ (en México) y el 65\% (en Colombia) de los hogares presentan carencias en el indicador de TNR. Con respecto al indicador de TR, la tasa de recuento oscila entre el 19\% (Colombia) y el 34\% (Uruguay) de los hogares. En los cuatro países, se observa que el menor porcentaje de hogares con carencias se presenta en las dimensiones asociadas a las condiciones de vivienda de los hogares (excepto saneamiento), e inasistencia escolar. Llaman la atención las altas tasas de recuento bruto de los indicadores de autonomía económica en todos los países.

La tasa de recuento ( $\mathrm{H}$ o incidencia) de los hogares en situación de pobreza disminuye de manera sustantiva a medida que aumenta el porcentaje de carencias considerado (punto de corte o $k$ estimado considerado como un umbral de carencias que distingue entre los pobres multidimensionales y los no pobres). En el grafico 5 se señala que entre el $80 \%$ y el $98 \%$ de los hogares presentan al menos un $10 \%$ de carencias. Por último, aplicando un umbral multidimensional $(k)$ equivalente al $30 \%$ de carencias, la tasa de recuento multidimensional oscila entre el $25 \%$ (en el Uruguay) y el 78\% (en el Ecuador) de los hogares (véase el gráfico 5 , panel izquierdo). Para estos hogares, el promedio de carencias oscila entre el $35 \%$ y el $45 \%$ (gráfico 6 , panel derecho). En el gráfico 6 se aprecian los resultados de $\mathrm{M}_{0}{ }^{13}$, según los diferentes valores de $k$. En el resto del capítulo se analizarán los resultados con un $k=30 \%$.

13 En la metodología de Alkire y Foster (2007) se define la pobreza multidimensional, o tasa de recuento ajustada, como sigue: $M_{0}=H^{*} A$. 
GRÁFICO 4

Tasa de recuento bruta por indicador de carencias

(En porcentajes de los hogares)
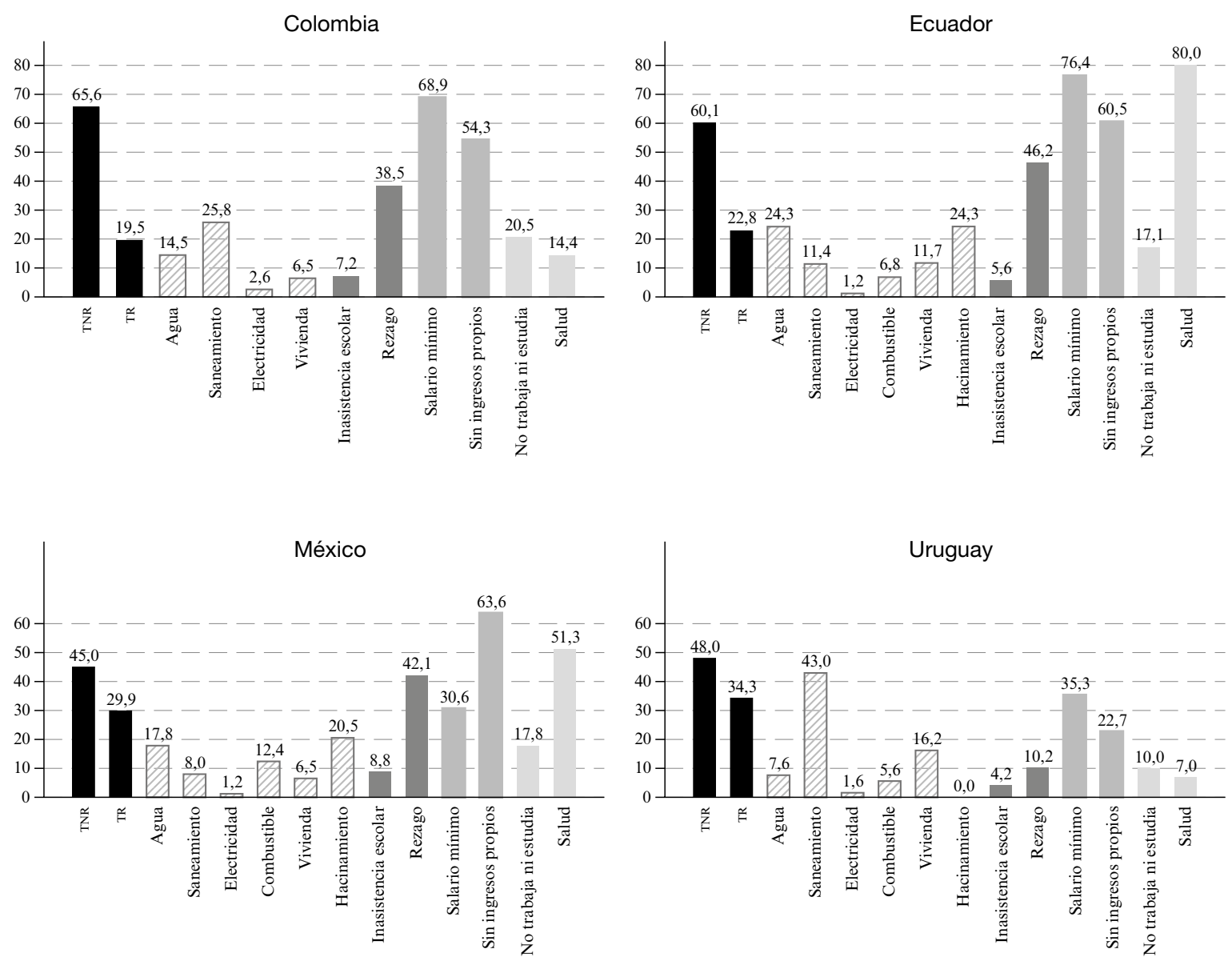

Fuente: Elaboración propia sobre la base de tabulaciones de las encuestas sobre uso del tiempo (EUT) de Colombia (2012), el Ecuador (2012), México (2009) y el Uruguay (2007).

Nota: TR: Trabajo remunerado; TNR: Trabajo no remunerado. 
GRÁFICO 5

Tasa de recuento $(\mathrm{H})$ y promedio de carencias entre los hogares pobres (A)

(Porcentaje de hogares y porcentaje de carencias promedio)
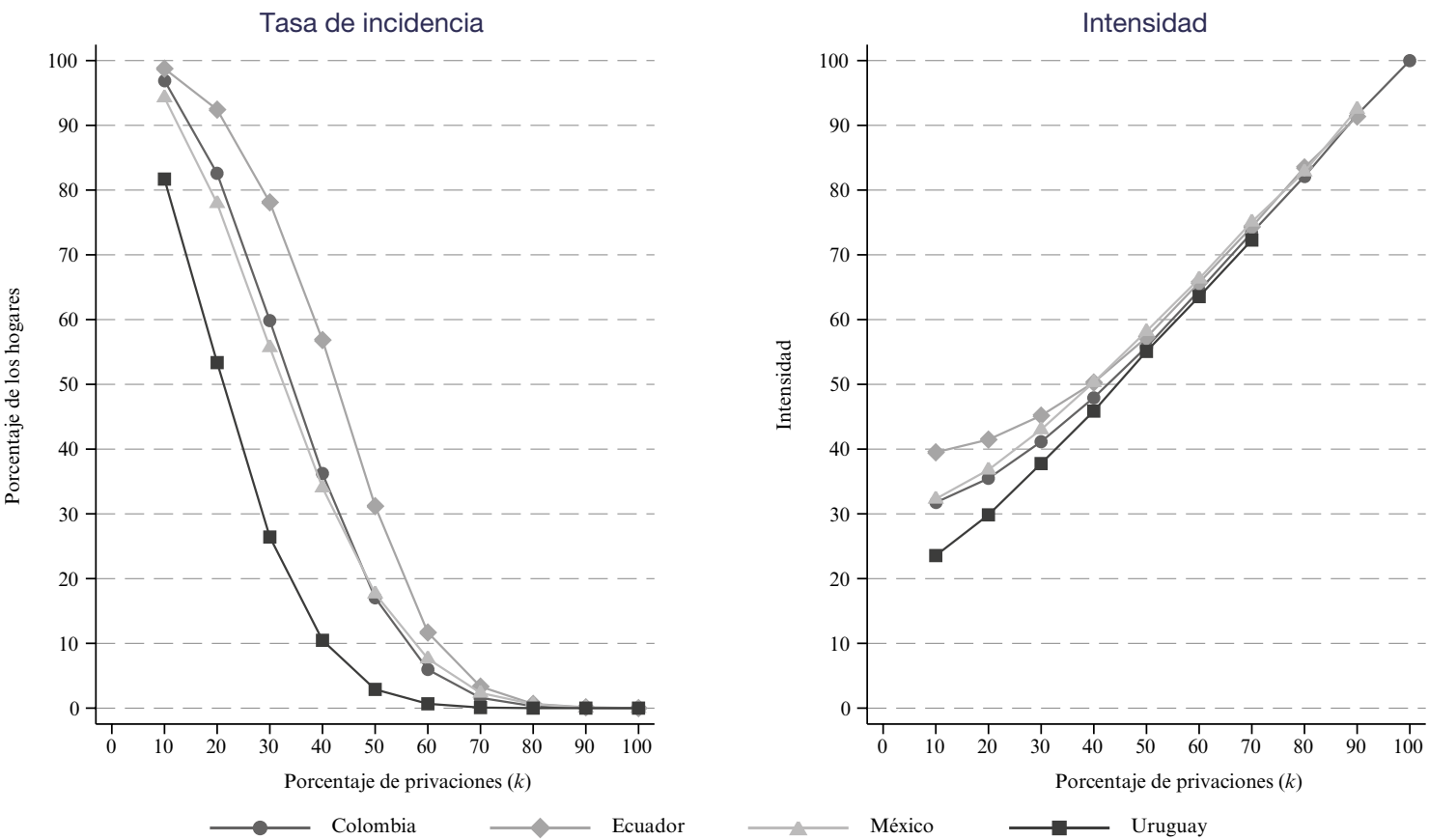

Fuente: Elaboración propia sobre la base de tabulaciones de las encuestas sobre uso del tiempo (EUT) de Colombia (2012), el Ecuador (2012), México (2009) y el Uruguay (2007).

GRÁFICO 6

Indicador multidimensional (Índice M subíndice 0)

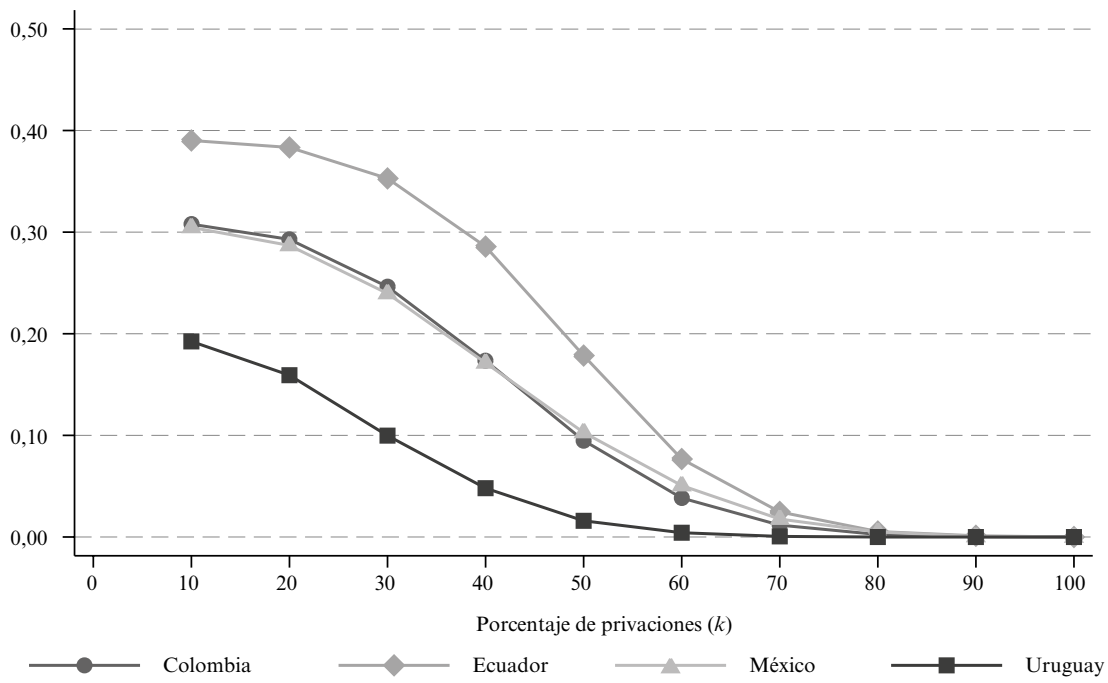

Fuente: Elaboración propia sobre la base de tabulaciones de las encuestas sobre uso del tiempo (EUT) de Colombia (2012), el Ecuador (2012), México (2009) y el Uruguay (2007). 
Una de las propiedades más útiles en términos de política pública de la metodología de pobreza multidimensional de Alkire y Foster (2007) es su capacidad de ser descompuesta ${ }^{14}$. Las mayores contribuciones al indicador multidimensional $\left(\mathrm{M}_{0}\right)$ a nivel nacional provienen de las siguientes dimensiones: autonomía económica, tiempo, exclusión y educación. En el gráfico 7 se puede ver el detalle para cada país.

\section{Descomposición del indicador multidimensional: análisis por tipo de hogar}

El indicador multidimensional permite capturar distintos niveles de carencias según tipo de hogar. La incidencia de la pobreza multidimensional de tiempo y condiciones sociales, controlando por tipo de hogar, es mayor para los hogares compuestos y extendidos. Es importante destacar que la variabilidad de la incidencia de la pobreza

14 Esta propiedad es extremadamente útil para generar perfiles de pobreza y focalizarse en grupos de gran pobreza. entre los tipos de hogares se mueve en un rango entre un $15 \%$ y un $85 \%$ con un $k=30 \%$. Sin embargo, la variabilidad de la intensidad de la pobreza entre los cinco tipos de hogar en situación de pobreza es menor que la incidencia, dado que sus valores se sitúan en un rango entre un $34 \%$ y un $45 \%$, porcentajes que representan los promedios de carencias experimentadas por cada hogar (véase el gráfico 8).

La identificación de la contribución porcentual de los tipos de hogar a la incidencia y la intensidad del indicador multidimensional con un $k=30 \%$ indica que los hogares biparentales contribuyen en mayor proporción tanto a la tasa de incidencia y la intensidad como al $\mathrm{M}_{0}$ en comparación con los otros tipos de hogar (en el gráfico 9 se observa la contribución relativa al $\mathrm{M}_{0}$ ). Este hallazgo visibiliza a los hogares biparentales como aquellos en los que la división sexual del trabajo y su efecto en la carencia de tiempo y privaciones en otros aspectos relativos a las condiciones de vida (vivienda, energía y acceso a agua y saneamiento de un hogar) son mayores que en otros tipos de hogares. Los hogares unipersonales son aquellos que presentan las menores

GRÁFICO 7

Colombia, Ecuador, México y Uruguay: contribución porcentual de las dimensiones al indicador multidimensional (M subíndice 0 )

(En porcentajes)

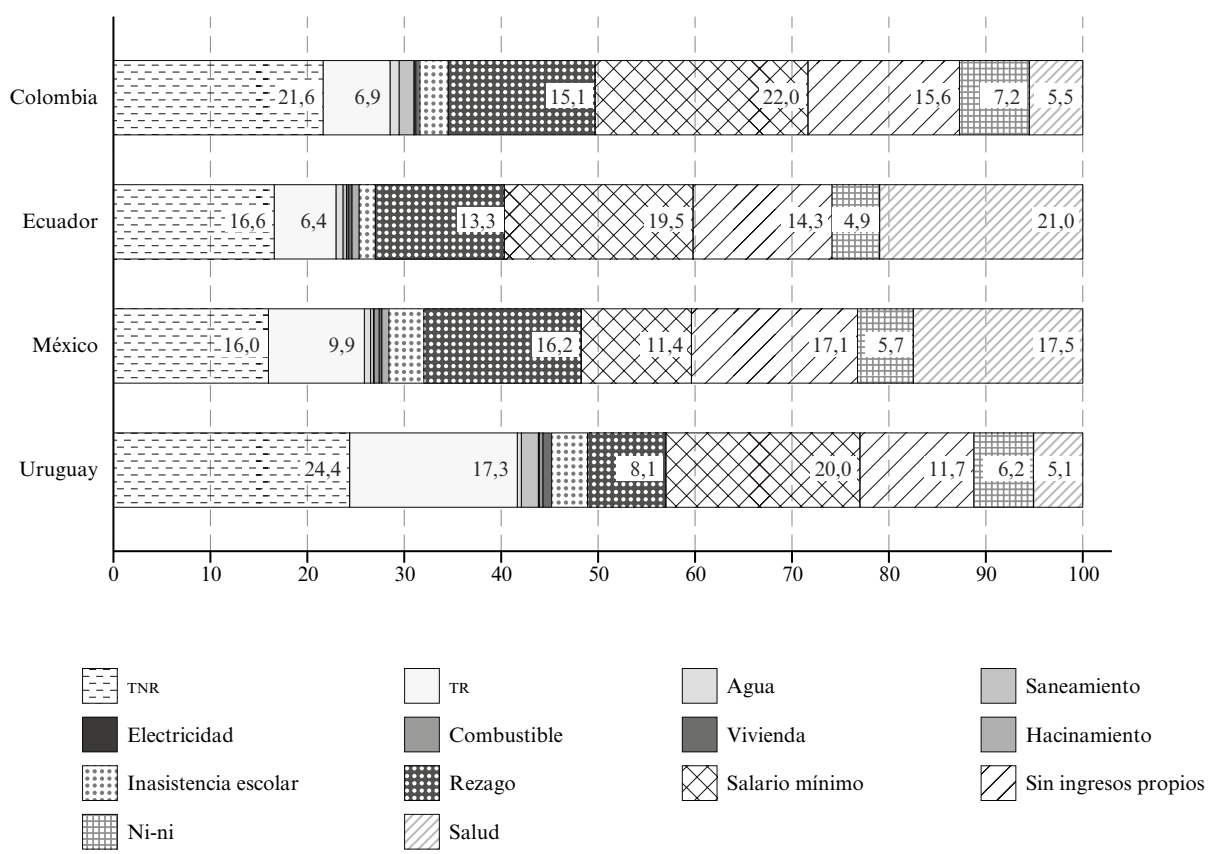

Fuente: Elaboración propia sobre la base de tabulaciones de las encuestas sobre uso del tiempo (EUT) de Colombia (2012), el Ecuador (2012), México (2009) y el Uruguay (2007).

Nota: TR: Trabajo remunerado; TNR: Trabajo no remunerado; Ni-ni: No estudia ni trabaja. 
GRÁFICO 8

Tasa de recuento $(\mathrm{H})$ e intensidad $(\mathrm{A})$ de los hogares según tipo de hogar (En porcentajes)
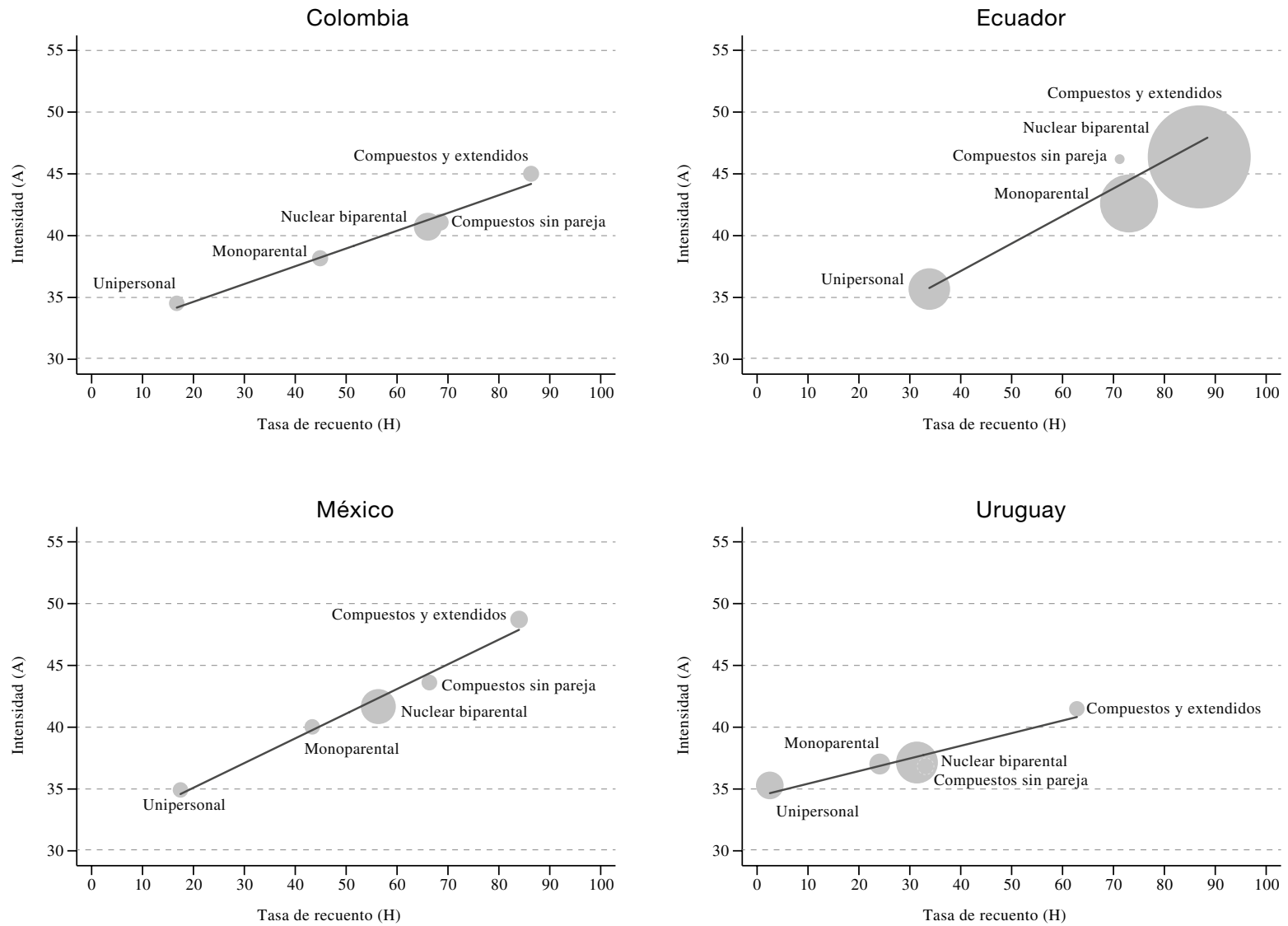

Fuente: Elaboración propia sobre la base de tabulaciones de las encuestas sobre uso del tiempo de Colombia (2012), el Ecuador (2012), México (2009) y el Uruguay (2007).

contribuciones a estas variables. Un argumento que explicaría esta menor contribución porcentual es el tipo de indicadores que integran la dimensión tiempo, debido a que, por ejemplo, el indicador de tiempo para el cuidado y trabajo domésticos tiene por objeto integrar la justicia y el componente género en el contexto de un hogar y la asignación de tiempo a ambos tipos de TNR. Por consiguiente, los hogares unipersonales no presentarían carencias en este indicador dado que por su estructura no existe una contraparte con el que visibilizar la presencia excesiva de la división sexual del trabajo entre sus integrantes. 

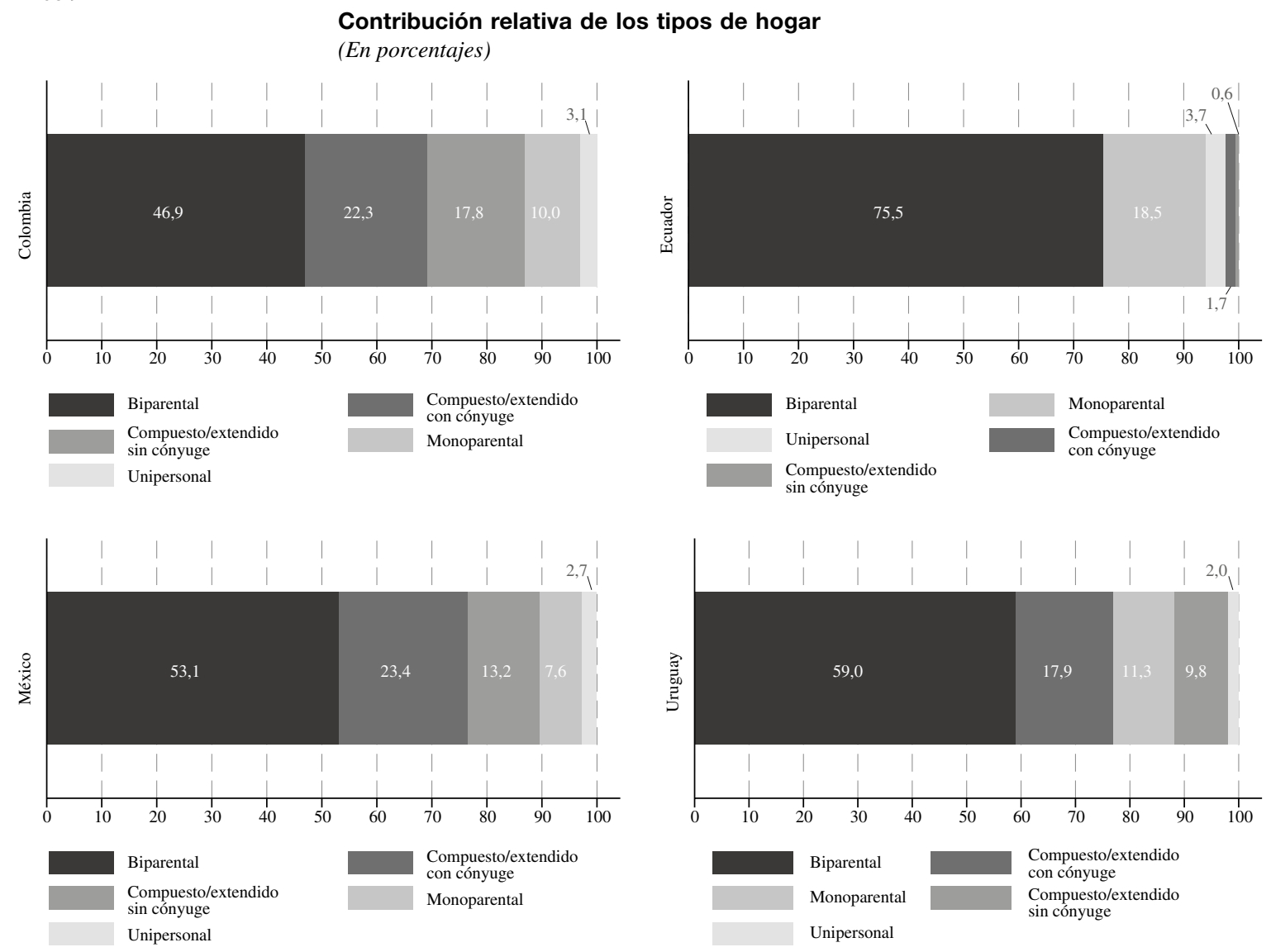

Fuente: Elaboración propia sobre la base de tabulaciones de las encuestas sobre uso del tiempo de Colombia (2012), el Ecuador (2012), México (2009) y el Uruguay (2007).

\section{$\mathrm{V}$}

\section{Reflexiones finales}

La preocupación por la garantía de los derechos de las mujeres y la creación de capacidades individuales, familiares, comunitarias e institucionales que generen espacios y oportunidades para el ejercicio de libertades sustantivas para ellas, emergieron en un contexto de desigualdad socioeconómica y carencia de justicia distributiva. Esta preocupación tiene hoy connotaciones distintas a las que tuvo a mediados del siglo xx. Hoy los esfuerzos políticos y sociales están centrados en el desarrollo de mecanismos que promuevan el desarrollo de capacidades humanas, garanticen los derechos y eliminen toda forma de discriminación contra las mujeres.
Estos cambios de visión deberían repercutir en los derechos y el desarrollo de capacidades en cuatro ámbitos. En primer lugar, en la deslegitimización de todas las formas de violencia social, cultural y económica que implican que las mujeres sean limitadas en la toma de decisiones para el uso y desarrollo del conjunto o la combinación de capacidades que ellas valoren (entre las que se hallan la capacidad de ocio, el TR y el TNR). Esta deslegitimización debe además ser acompañada de la definición de políticas públicas que ejerzan su acción comprendiendo en profundidad los contextos y sectores de la población femenina, donde la exclusión social y 
las desigualdades se han acumulado y reforzado a través de su ciclo de vida.

Segundo, los esfuerzos por identificar los obstaculizadores y los facilitadores del desarrollo humano ya son parte de los objetivos entre los hacedores de políticas. No obstante, desde el enfoque de desarrollo humano y capacidades es crucial identificar las capacidades que son virtuosas, en términos de que sus características generan espacios para el desarrollo de otras capacidades (Wolff y De-Shalit, 2007).

Tercero, los efectos de la división sexual del trabajo en las condiciones de vida de los hogares y de sus miembros se abordan de mejor manera desde una perspectiva multidimensional, donde las carencias, la vulneración de derechos y los mecanismos de exclusión no solo se combinan entre el poder político, el reconocimiento, las oportunidades para ejercer la agencia y la justicia social, sino que también impactan en la distribución y el ejercicio de los derechos humanos. En estas circunstancias, una proporción de los hogares pueden experimentar cambios relevantes en su situación socioeconómica, positivos y negativos, como consecuencia del acceso al empleo de sus miembros, lo que podría, o no, generar posteriormente cambios en las relaciones de poder en el interior de sus hogares.

En cuarto lugar, las carencias de recursos tangibles (ingresos) e intangibles (capital humano y social), condicionan contextos donde se perpetúen las barreras al desarrollo de capacidades para el trabajo remunerado y la autonomía económica. Estas carencias se traducen en obstaculizadores al desarrollo humano, dado que aumentan la probabilidad de que los hogares tengan inseguridad con respecto a la provisión y distribución de bienes, recursos y reconocimiento entre sus miembros.

Las limitaciones a los cambios en la visión sobre la problemática social son determinados, en parte, por los cuatro ámbitos citados y tienen importantes implicancias para las políticas sociales, cuyo objeto es aumentar la participación femenina en el mercado del trabajo. De acuerdo con una visión multidimensional y dinámica, los problemas de la carencia de justicia distributiva en el interior del hogar y la inequidad que esta produce no se agotan en las condiciones de precariedad material en que viven los grupos de menores ingresos y oportunidades efectivas para el logro de sus funcionamientos y el desarrollo de las capacidades que ellos valoran. En consecuencia, desde una visión multidimensional, las carencias de los individuos no se resuelven mediante programas unidimensionales, sino que requieren estrategias políticas que aumenten la libertad sustantiva de los individuos mediante, por ejemplo, programas intersectoriales. Así, es posible plantear que en aquellos hogares donde al menos uno de sus integrantes carece de autonomía económica y que además presentan pobreza de tiempo, los efectos de los determinantes de la pobreza en el bienestar individual serían más estructurales y no transitorios, lo que contrasta con los supuestos respecto de la transitoriedad de la pobreza de tiempo durante el ciclo de vida de un individuo. En este contexto, resultará fundamental desarrollar estrategias que ataquen el fenómeno multidimensional de las carencias de los hogares y sus individuos mediante programas sociales capaces de contribuir a superar dichas carencias, aun cuando solo uno de sus miembros se encuentre privado de alguno de los factores o determinantes de una condición de vida digna. Junto con lo anterior, es importante dinamizar las políticas que tienen por objetivo erradicar prácticas discriminatorias en los hogares, las instituciones sociales formales e informales y en el mercado laboral.

La búsqueda de una visión multidimensional de la política social complementaria a estrategias focalizadas en la superación de la pobreza de ingresos debe incluir un debate respecto del bienestar y condiciones de vida, no solo de la proporción de la población en situación de pobreza, sino también considerar a los sectores vulnerables (que presentan dificultades para consolidar su situación económica). Por cierto que la importancia relativa de los determinantes de la pobreza entre ambos grupos de ingresos es distinta, pero en ambos casos, cuando las mujeres tienen un TR, sus oportunidades de desarrollar otras capacidades se ven limitadas por la carga excesiva de TNR. Esto se evidencia en el presente artículo: la alta contribución de la mujer al total del TNR requerido para que un hogar funcione o supla las demandas de cuidado y TNR de sus dependientes e inclusive no dependientes.

Asimismo, emerge de este trabajo un conjunto de acciones relevantes para la formulación y el diseño de políticas que promuevan el ejercicio de libertades sustantivas que las personas valoran, para lo cual es requisito que el modelo de desarrollo cambie su mirada homogeneizadora de habilidades y competencias y garantías mínimas por un enfoque basado en el desarrollo de las capacidades humanas en América Latina.

Un primer desafío es avanzar hacia un cambio de visión respecto de los determinantes del bienestar, que tradicionalmente se han utilizado como proxy de las condiciones de vida, e incluir el impacto de la acumulación de inequidades y carencias tangibles e intangibles en las mediciones del bienestar. El segundo desafío radica en avanzar hacia un modelo de desarrollo nacional sobre la base de la igualdad de género. En esta visión se debería identificar la contribución de los 
determinantes de las carencias de tiempo y condiciones de vida. Luego, sobre la base de este análisis será posible identificar patrones de convergencia y divergencia entre los distintos países. La identificación de estos patrones contribuirá al desarrollo de una "tipología" basada en las características de modelos de desarrollo humano y capacidades que permitan en seguida abordar el análisis de políticas de cuidado y promotoras de la incorporación de las mujeres a la fuerza laboral desde una perspectiva multidimensional.

\section{Bibliografía}

Adkins, Ch. y S. Premeaux (2012), "Spending time: the impact of hours worked on work. family conflict", Journal of Vocational Behavior, vol. 80, $\mathrm{N}^{\circ}$ 2, Amsterdam, Elsevier.

Alkire, S. (2002), "Dimensions of human development", World Development, vol. 30, $\mathrm{N}^{\circ} 2$, Amsterdam, Elsevier.

Alkire, S. y J. Foster (2013), "OpHI Summer School on Multidimensional Poverty Analysis 2013", Washington, D.C., Oxford Poverty and Human Development Initiative (OPHI). (2007), "Recuento y medición multidimensional de la pobreza", Documento de Trabajo OPHI, $\mathrm{N}^{\circ} 7$, Oxford, Universidad de Oxford.

Ballet, J. y otros (2014), Freedom, Responsibility and Economics of the Person, Nueva York, Routledge.

Bardasi, E. y Q. Wodon (2009), "Working long hours and having no choice: time poverty in Guinea", Policy Research Working Paper Series, $\mathrm{N}^{\circ}$ 4961, Washington, D.C., Banco Mundial.

Bittman, M. y otros (2005), "The time-pressure illusion: discretionary time vs. free time", Social Indicators Research, vol. 73, $\mathrm{N}^{\circ} 1$, Springer.

Bonke, J. y M. Browning (2003), "The distribution of well-being and income within the household", Welfare Distribution Working Paper, $\mathrm{N}^{\circ} 1 / 2003$, The Danish National Institute of Social Research.

Brighouse, H. e I. Robeyns (eds.) (2010), Measuring Justice: Primary Goods and Capabilities, Cambridge, Cambridge University Press.

Burchardt, T. (2010), "Time, income and substantive freedom: a capability approach", Time and Society, vol. 19, № 3, SAGE.

Carrasco, C. (1991), El trabajo doméstico. Un análisis económico, Madrid, Ministerio de Empleo y Seguridad Social.

Carrasco, C., C. Borderías y T. Torns (eds.) (2011), El trabajo de cuidados. Historia, teoría y políticas, Madrid, Libros de la Catarata.

Chiappori, P. y otros (2011), "Are intra-household allocations policy neutral? Theory and empirical evidence", IZA Discussion Paper, $\mathrm{N}^{\circ}$ 5594, Bonn, Institute for the Study of Labour (IZA).

CEPAL (Comisión Económica para América Latina y el Caribe) (2014), Pactos para la igualdad: hacia un futuro sostenible (LC/G.2586(SES.35/3)), Santiago.

(2013a), Observatorio de Igualdad de Género. Informe anual 2012. Los bonos en la mira: aporte y carga para las mujeres (LC/G.2561/Rev.1), Santiago.

(2013b), Panorama Social de América Latina 2013 (LC/G.2580), Santiago.

(2013c), Redistribuir el cuidado: el desafío de las políticas (LC/G.2568-P), Coral Calderón Magaña (coord.), Santiago. (2010a), “Qué Estado para qué igualdad?” (LC/G. 2450(CRM.11/3)), Santiago.

(2010b), "Consenso de Brasilia" [en línea] http://www. eclac.cl/mujer/noticias/paginas/5/40235/ConsensoBrasilia_ESP. pdfXI.

Díaz, Y. (2013), "Counting Deprivations: a Household-based Multidimensional Approach" [en línea] http://www.ophi.org. uk/wp-content/uploads/Present_YD_Nov2013.pdf.

Douthitt, R. (1994), “Time to do the chores?' Factoring homeproduction needs into measures of poverty", Discussion Paper, $\mathrm{N}^{\circ}$ 1030-94, Madison, Universidad de Wisconsin [en línea http://www.irp.wisc.edu/publications/dps/pdfs/dp103094.pdf.
Durán, M.A. (2007), El valor del tiempo. ¿Cuántas horas te faltan al día?, Madrid, Editorial Espasa Calpe.

Feres, J.C. y X. Mancero (2001), "Enfoques para la medición de la pobreza. Breve revisión de la literatura", serie Estudios Estadísticos y Prospectivos, № 4 (LC/L.1479-P), Santiago, Comisión Económica para América Latina y el Caribe (CEPAL).

Folbre, N. (2006), "Measuring care: gender, empowerment, and the care economy", Journal of Human Development, vol. 7, $\mathrm{N}^{\circ} 2$.

Fraser, N. (2009), Scales of Justice: Reimagining Political Space in a Globalizing World, Nueva York, Columbia University Press.

Fraser, N. y A. Honneth (2006), ¿Redistribución o reconocimiento? Un debate político-filosófico, Madrid, Ediciones Morata.

Gammage, S. (2009), "Género, pobreza de tiempo y capacidades en Guatemala: un análisis multifactorial desde una perspectiva económica" (LC/MEX/L.955), Ciudad de México, Sede Subregional de la CEPAL en México.

Goodin, R. y otros (2008), Discretionary Time: A New Measure of Freedom, Cambridge, Cambridge University Press.

Gronau, R. (1977), "Leisure, home production, and work. The theory of the allocation of time revisited", The Journal of Political Economy, vol. 85, $\mathrm{N}^{\circ}$ 6, Chicago, University of Chicago Press, diciembre.

Hobfoll, S.E. (1989), "Conservation of resources: a new attempt at conceptualizing stress", American Psychologist, vol. 44 , $\mathrm{N}^{\circ}$ 3, Washington, D.C., American Psychological Association.

Jain, D. (2013), "Incorporación de la perspectiva de género en el progreso económico", Redistribuir el cuidado: el desafío de las políticas (LC/G.2568-P), Coral Calderón Magaña (coord.), Santiago.

Johnstone, M.B. (1960), How to Live Every Day of Your Life, Indianapolis, Bobbs-Merrill.

Merino, A. (2012), "La pobreza de tiempo e ingresos en Guatemala", Cuadernos de Trabajo, $\mathrm{N}^{\circ} 3$, Entidad de las Naciones Unidas para la Igualdad de Género y el Empoderamiento de las Mujeres (ONU-Mujeres).

(2010), "La pobreza multidimensional y el tiempo de las mujeres mexicanas", Cuadernos de Trabajo, $\mathrm{N}^{\circ} 22$, Entidad de las Naciones Unidas para la Igualdad de Género y el Empoderamiento de las Mujeres (onU-Mujeres)/Instituto Nacional de las Mujeres.

Nussbaum, M. (2011), Creating Capabilities. The Human Development Approach, Cambridge, Massachusetts, Harvard University Press.

(2003), "Capabilities as fundamental entitlements: Sen and social justice", Feminist Economics, vol. 9, N²-3, Taylor \& Francis.

OIT (Organización International del Trabajo) (2013), Panorama Laboral 2013. América Latina y el Caribe, Lima.

oms (Organización Mundial de la Salud) (1989), Health Principles of Housing, Ginebra.

ONU-Mujeres (Entidad de las Naciones Unidas para la Igualdad de Género y el Empoderamiento de las Mujeres) (s/f), "Medir el trabajo no remunerado (TNR) y el uso del tiempo (UdT): visibilizar la contribución de las mujeres a la economía y sociedad" [en línea] http://www2.unwomen.org/ /media/field\%20office\%20 americas/documentos/publicaciones/contribuci\%C3\%B3n\%20 mujeres.pdf?v=1\&d=20150625T091450. 
Pick, S. y J. Sirkin (2010), Breaking the Poverty Cycle: The Human Basis for Sustainable Development, Nueva York, Oxford University Press.

Robeyns, I. (2005), "Selecting capabilities for quality of life measurement", Social Indicators Research, vol. 74, $\mathrm{N}^{\circ} 1$, Springer.

(2003), "Sen's capability approach and gender inequality: selecting relevant capabilities", Feminist Economics, vol. 9, $\mathrm{N}^{\circ}$ 2-3, Taylor \& Francis.

Sen, A. (2004), "Capabilities, lists, and public reason: continuing the conversation", Feminist Economics, vol. 10, N ${ }^{\circ} 3$, Taylor \& Francis.

(2000), Desarrollo y libertad, Barcelona, Editorial Planeta. (1992), Inequality Reexamined, Oxford, Oxford University Press.
Stiglitz, J.E., A. Sen y J.P. Fitoussi (2009), "Report by the Commission on the Measurement of Economic Performance and Social Progress" [en línea] http://www.stiglitz-sen-fitoussi. fr/documents/rapport_anglais.pdf.

Vickery, C. (1977), "The time-poor: a new look at poverty", Journal of Human Resources, vol. 12, N ${ }^{\circ}$, Wisconsin, University of Wisconsin Press.

Warren, T. (2003), "Class-and gender-based working time? Time poverty and the division of domestic labour", Sociology, vol. $37, \mathrm{~N}^{\circ} 4$, SAGE.

Wolff, J. y A. De-Shalit (2007), Disadvantage, Oxford, Oxford University Press.

Zacharias, A. (2011), "The measurement of time and income poverty", Working Paper, $\mathrm{N}^{\circ}$ 690, Levy Economics Institute of Bard College [en línea] http://www.levyinstitute.org/pubs/ wp_690.pdf. 